\title{
Review \\ Specific microRNAs for Modulation of Autophagy in Spinal Cord Injury
}

\author{
Rhett Visintin ${ }^{1}\left(\mathbb{D}\right.$ and Swapan K. Ray ${ }^{2, *(1)}$ \\ 1 Department of Chemistry and Biochemistry, University of South Carolina, Columbia, SC 29208, USA; \\ rhettv@email.sc.edu \\ 2 Department of Pathology, Microbiology, and Immunology, University of South Carolina School of Medicine, \\ Columbia, SC 29209, USA \\ * Correspondence: swapan.ray@uscmed.sc.edu; Tel.: +1-803-216-3420; Fax: +1-803-216-3428
}

Citation: Visintin, R.; Ray, S.K. Specific microRNAs for Modulation of Autophagy in Spinal Cord Injury. Brain Sci. 2022, 12, 247. https:// doi.org/10.3390/brainsci12020247

Academic Editor: Thomas

Haynes Hutson

Received: 31 December 2021

Accepted: 6 February 2022

Published: 11 February 2022

Publisher's Note: MDPI stays neutral with regard to jurisdictional claims in published maps and institutional affiliations.

Copyright: () 2022 by the authors. Licensee MDPI, Basel, Switzerland. This article is an open access article distributed under the terms and conditions of the Creative Commons Attribution (CC BY) license (https:// creativecommons.org/licenses/by/ $4.0 /)$.

\begin{abstract}
The treatment of spinal cord injury (SCI) is currently a major challenge, with a severe lack of effective therapies for yielding meaningful improvements in function. Therefore, there is a great opportunity for the development of novel treatment strategies for SCI. The modulation of autophagy, a process by which a cell degrades and recycles unnecessary or harmful components (protein aggregates, organelles, etc.) to maintain cellular homeostasis and respond to a changing microenvironment, is thought to have potential for treating many neurodegenerative conditions, including SCI. The discovery of microRNAs (miRNAs), which are short ribonucleotide transcripts for targeting of specific messenger RNAs (mRNAs) for silencing, shows prevention of the translation of mRNAs to the corresponding proteins affecting various cellular processes, including autophagy. The number of known miRNAs and their targets continues to grow rapidly. This review article aims to explore the relationship between autophagy and SCI, specifically with the intent of identifying specific miRNAs that can be useful to modulate autophagy for neuroprotection and the improvement of functional recovery in SCI.
\end{abstract}

Keywords: spinal cord injury (SCI); autophagy; neurodegeneration; miRNAs, miRNAs for modulation of autophagy; neuroprotection; functional recovery

\section{Introduction}

Alteration of the status of autophagy via microRNAs (miRNAs) may profoundly influence the course of pathogenesis and locomotor recovery in spinal cord injury (SCI). Our increasing understanding of the biochemical mechanisms of autophagy and miRNAs and their interactions in preclinical models of SCI will open new therapeutic avenues for successful treatment of the patients who become the victims of this devastating neurological condition. Autophagy is a general term that can refer to several distinct cellular processes, including macroautophagy, chaperone-mediated autophagy (CMA), and microautophagy. This review article focuses specifically on macroautophagy, which will hereafter be referred to as "autophagy". Autophagy is utilized by a cell to break down and recycle its numerous substrates, either in "bulk autophagy", targeting essentially random volumes of cytoplasmic contents, or in "selective autophagy", targeting specific substrates, including protein aggregates, organelles such as mitochondria, parts of the nucleus, invading bacteria, proteasomes, peroxisomes, lysosomes, and others [1]. Over 40 proteins that make up the core autophagy machinery, known as autophagy-related (ATG) proteins, are highly conserved among eukaryotes $[2,3]$ and have been most extensively studied in yeast, though analogs in several model organisms, as well as humans, have been identified [1]. Autophagy involves several steps (Figure 1), beginning with the formation of a double-membrane vesicle (called an autophagosome) from a nucleating membrane (called the phagophore or induction membrane) at sites on the endoplasmic reticulum known as omegasomes [4]. 


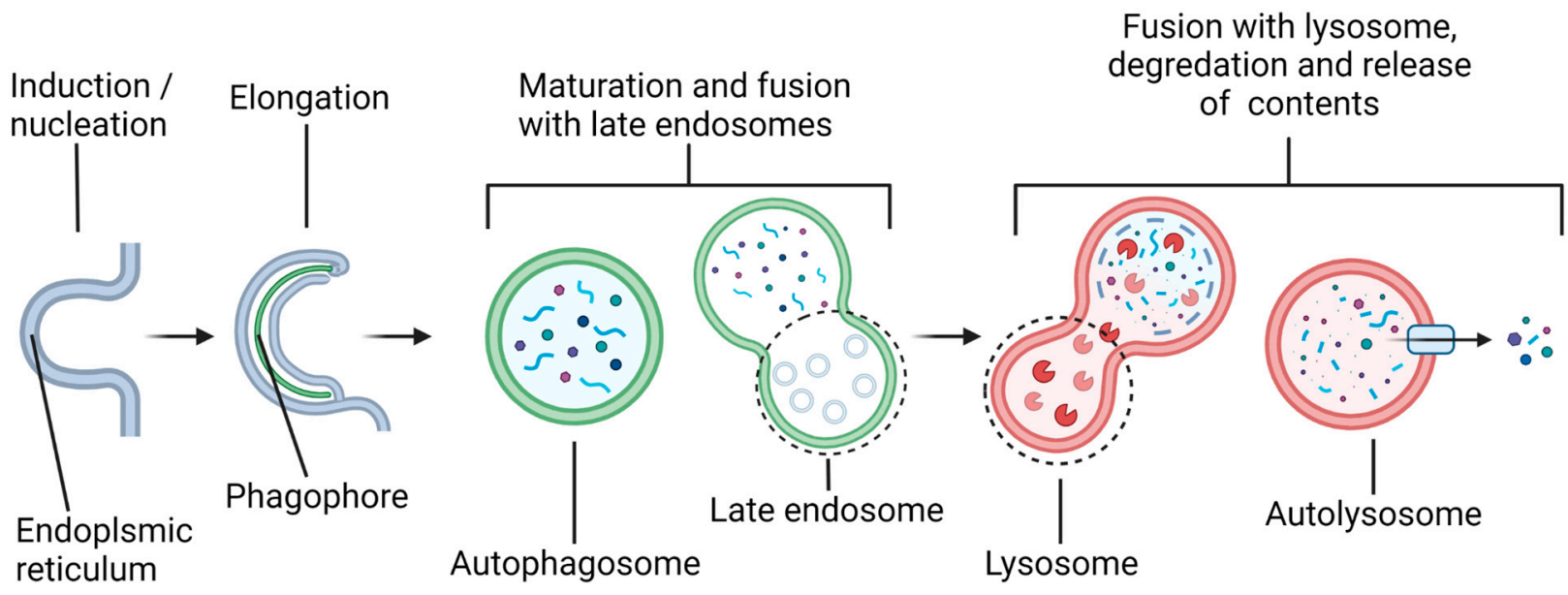

Figure 1. Overview of the autophagy pathway. Induction of autophagy begins with the formation of a cup-shaped domain of the endoplasmic reticulum called an omegasome. The nascent autophagosome, called a phagophore or induction membrane, is formed from the omegasome, and it grows until it has sealed around its cargo and produced a mature autophagosome. The autophagosome subsequently fuses with a late endosome, also known as multivesicular bodies (MVBs), ultimately merging with a lysosome or lysosomes. Acid hydrolases in the lysosome degrade the inner autophagosomal membrane and its contents into the cellular building blocks, which, afterwards, are released into the cytosol for recycling in the cell.

As the phagophore expands, it envelops cargo destined to be degraded after maturation of the autophagosome and fusion with a lysosome(s). The vesicle resulting from this fusion is called an autolysosome, and it is here that lysosomal acid hydrolases degrade the autophagosomal contents into their basic units (amino acids, nucleotides, etc.), which are subsequently released back into the cytosol for recycling. The autophagy pathway is active at the basal level to maintain cellular homeostasis but is also activated by several stress signals, such as an increase in the AMP/ATP ratio due to starvation (via activation of the $5^{\prime}$ AMP-activated protein kinase or AMPK) or excessive reactive oxygen species (ROS) produced by the defective mitochondria, among others $[5,6]$. The total degradative throughput due to autophagy in the cell is called autophagic flux. The genetic or pharmacological modulation of autophagic flux has been implicated in numerous pathophysiological conditions, including cancers, neurodegenerative diseases, and SCI [7-9].

Acute $\mathrm{SCI}$ is a debilitating condition, which exerts significant physical, psychological, and economic tolls on the SCI patients, their families, and the healthcare system. The incidence of traumatic SCI is about 54 per 1,000,000 people (17,900 new cases per year) in the United States, at a total cost of around $\$ 15.7$ billion dollars per year [10]. Complications and prognosis depend on the location and severity of the injury, with cervical and thoracic SCI associated with poorer and poor outcomes, respectively [11]. Some potential complications of SCI include partial or full paralysis below the injury level; cardiovascular issues; autonomic dysreflexia; joint degradation and/or ossification; reduced respiratory function; chronic pain; and sexual, urinary, and gastrointestinal dysfunctions, among others [12] Due to the low innate regenerative ability of the spinal cord, recovery in SCI patients is usually incomplete, and the current therapies are limited in their efficacy [11]. Due to this grim situation, therapies targeting neuroprotection and neuroregeneration after SCI are an active area of research $[13,14]$. Due to its prominent role in cellular homeostasis, cellular stress responses, and programmed cell death, the modulation of autophagy presents a promising avenue for the treatment of SCI.

\section{Different Phases of Traumatic SCI and Its Complex Pathophysiology}

The progression of traumatic SCI is divided into two major phases: primary and secondary injuries. Primary injury is usually sudden and occurs due to mechanical forces 
(such as injury from a car accident or fall), resulting in fractures in the vertebrae and compression, distraction, and/or transection of the spinal cord $[15,16]$. A primary injury to the spinal cord triggers a secondary injury, which is characterized by a signaling cascade creating a microenvironment that results in further damage to the spinal cord and inhibits neuroregeneration. Secondary injuries can be further divided into acute (minutes to hours after primary injury), subacute (days to weeks after primary injury), and chronic phases (weeks to months after primary injury), though these phases are not clearly delineated and may overlap (Figure 2). Acute secondary injury is characterized by events including ischemia-reperfusion injury, the death of cells due to mechanical insult, necrosis resulting from glutamate excitotoxicity and ionic imbalance, and inflammation due to the activation of resident microglia and astrocytes and exacerbated by the introduction of blood-born immune cells due to permeation of the blood-spinal cord barrier $[15,17,18]$. In the subacute phase, mitochondrial dysfunction due to an increased intracellular $\mathrm{Ca}^{2+}$ load and immune cell activation result in the production of ROS and reactive nitrogen species (RNS), damaging proteins, nucleic acids, and lipid membranes; these events subsequently cause the induction of apoptosis in and around the primary injury site or the lesion site. The activation of macrophages and death of oligodendrocytes lead to axonal demyelination and Wallerian degeneration [19]. Inflammation triggers the beginning of glial scar formation around the lesion perimeter by the activated reactive astrocytes. The chronic phase of SCI involves glial scar maturation through the formation of a pericyte/fibroblast-derived fibrotic core surrounded by an astrocytic outer layer, the formation of cysts (syringomyelia), and continued apoptosis and demyelination.

\section{Acute phase ( $<24 \mathrm{~h}$ after primary injury)}

- Compression, distraction and transection injuries

- Cell death due to mechanical forces

Disruption of blood-spinal cord barrie

Severe ionic imbalance

Glutamate toxicity
Inflammation

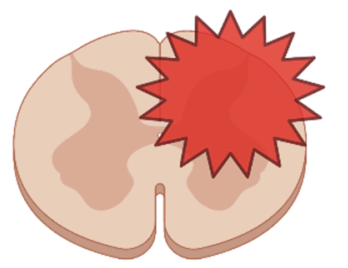

Sub-acute phase (days and weeks following acute phase)

- Mitochondrial dysfunction - ROS and RNS production - Inflammation and macrophage activation - Initiation of glial scar formation - Wallerian degeneration - Progressive demyelination

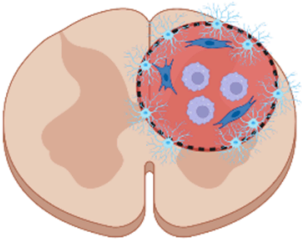

Chronic phase (months or more after primary injury)

- Maturation of glial scar and fibroblast core - Persistent inflammation due to infiltration of macrophages through blood-spinal cord barrier Continued demylination Minimal neuroregeneration - Cyst formation (syringomyelia)

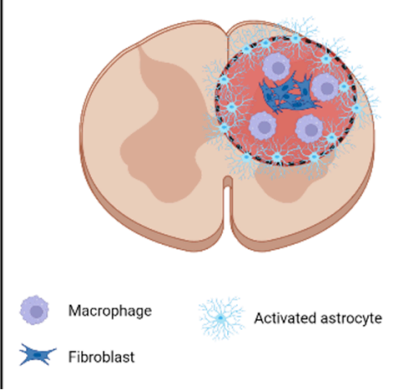

Figure 2. Secondary phases of SCI. After the primary traumatic injury (compression, distraction, transection, etc. of the spinal cord), the acute secondary phase immediately follows. Mechanical force ruptures cells and disturbs the blood-spinal cord barrier, allowing entrance of the blood-born immune cells into the lesion site. Glutamate excitotoxicity and disruption of the ionic balance led to mass necrosis. After about $24 \mathrm{~h}$, the subacute phase begins, marked by the initiation of an astrocyte-based glial scar around the lesion. The damaged mitochondria release damaging ROS, causing the axons near the lesion site to begin to demyelinate and die back. In the chronic stage, the glial scar matures, and a fibroblastic core is formed. The blood-spinal cord barrier remains disrupted, leading to chronic inflammation. Axon demyelination and degeneration continues. The presence of the scar chemically and physically hinders neuroregeneration.

Neuroregeneration during the subacute and chronic phases is inhibited by several factors. Debris from degraded oligodendrocytes and myelin contains three myelin-associated inhibitors, such as myelin-associated glycoprotein (MAG), oligodendrocyte-myelin gly- 
coprotein (OMgp), and Nogo-A, and the activators of the small GTPase RhoA and its downstream effector Rho kinase (ROCK) [20]. Activation of the RhoA-ROCK signaling pathway is associated with cell death and the loss of neural processes and synapses, causing perturbation of the information flow in the spinal cord. Activation of the RhoA-ROCK signaling pathway subsequently destabilizes cytoskeletal elements in neurite growth cones, leading to their collapse and the formation of dystrophic end bulbs [20]. Thus, inhibition of the RhoA-ROCK signaling pathway appears as a promising approach for treating SCI. Reactive astrocytes and oligodendrocyte precursor cells in the glial scar act as a physical and chemical barrier to neural regeneration, as they express neuroregeneration-inhibitory factors into the extracellular matrix, including chondroitin sulfate proteoglycans, which also activate the RhoA-ROCK signaling pathway [15,21]. Incomplete healing of the blood-spinal cord barrier (BSCB) leads to persistent macrophage infiltration into the lesion site, causing chronic inflammation $[19,22]$. Taken together, the complex interactions of the numerous factors that may promote or inhibit neuroregeneration depending on their localization and evolution over time indicate that a multifaceted approach to the treatment of SCI will be necessary to maximize the functional recovery.

\section{Biogenesis and Roles of miRNAs in the Context of SCI}

Various studies have indicated roles of miRNAs in neurodegeneration, as well as in neuroprotection, following SCI in preclinical models. Our goal is the exploration of specific miRNAs that increase the autophagy flux for neuroprotection in SCI. All miRNAs are short, noncoding RNA sequences (about 22 nucleotides long when mature), which have a significant regulatory effect on the post-transcriptional gene expression in many organisms by targeting and silencing mRNA transcripts. Since the initial identification of miRNAs in Caenorhabditis elegans nearly 30 years ago, our understanding of the scope of their influence has increased greatly [23-26]. Some miRNAs found in humans are evolutionarily conserved [27]. At least $60 \%$ of human genes are regulated by miRNAs, and there are virtually no human biological pathways that are not in some way affected by miRNAs [28]. Specific miRNAs play significant roles in the modulation of autophagy flux for the prevention of pathogenesis and promotion of neuroregeneration in SCI.

We will briefly describe the biogenesis of miRNAs and how they cause the silencing of mRNAs. Biogenesis begins with the transcription of a miRNA gene by RNA polymerase II (Pol II), though the transcription and subsequent processing can vary widely (Figure 3). In the canonical pathway, miRNA genes have their own promoters and are transcribed as pri-miRNAs; these genes may be located within or between protein-coding genes, and they may overlap introns, exons, and/or lncRNA genes [29]. Several clustered miRNA genes may be translated as a single polycistronic pri-miRNA. The relatively long pri-miRNA transcript subsequently folds into one or more hairpin structures before being processed in the nucleus by the microprocessor, a protein complex including the RNase III Drosha and two dimerized DiGeorge Critical Region 8 (DGCR8) proteins [30]. A microprocessor cleaves the pri-miRNA, leaving a $\sim 60-70$-nucleotide-long hairpin known as pre-miRNA. The pre-miRNA is transported out of the nucleus by Exportin- 5 and into the cytoplasm, where it is further processed by Dicer, another RNase III-type protein, which cleaves the molecule near the loop to produce mature double-stranded miRNA.

There are multiple forms of noncanonical miRNA biogenesis, which differ from the canonical pathway by skipping either the Drosha-regulated or Dicer-regulated steps [31]. Mirtrons are miRNA precursors formed by the spliceosome during mRNA intron removal, and they require debranching by the RNA debranching enzyme 1 (DBR1) but they are Drosha-independent. There is a single known Dicer-independent miRNA, miR-451, which is Drosha-dependent but subsequently processed directly by Argonaute 2 (AGO2) instead of Dicer. 


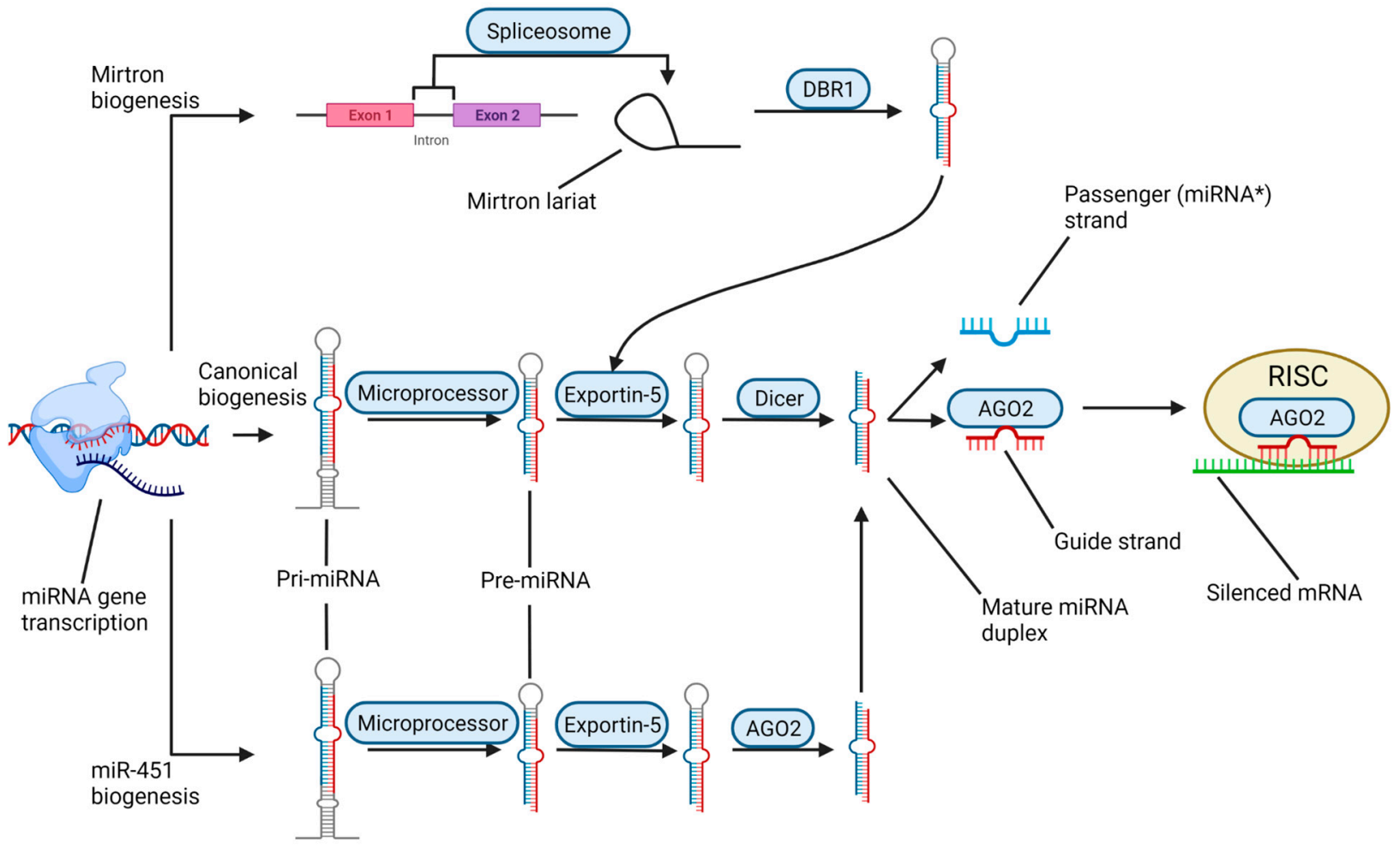

Figure 3. Biogenesis of matured miRNA. The first step for all pathways is the transcription of a miRNA gene by RNA Pol II. In the canonical pathway, the newly formed pri-miRNA hairpin is trimmed by the microprocessor complex in the nucleus to form a pre-miRNA, which is then transported out of the nucleus by Exportin-5. In the cytosol, Dicer cleaved the stem-loop of the premiRNA to form the mature miRNA duplex. The guide strand is separated from the passenger strand (miRNA*) and loaded onto Argonaute 2 (AGO2). AGO2 joins the RNA-induced silencing complex (RISC), where the target mRNA is selected by base-pairing with the loaded miRNA. Depending on the completeness of the match, the target mRNA may be either cleaved by AGO2 or be blocked from ribosomal translation. In the noncanonical pathway, Mirtrons are formed from introns during the splicing process. After forming a Mirtron loop, the nascent miRNA is debranched by the DBR1 and processed in the nucleus to form a pre-miRNA, which is then transported out of the nucleus by Exportin- 5 and subsequently follows the canonical pathway. The biogenesis of miR-451 is unique in that it is independent of Dicer; after being translated, processed by a microprocessor, and transported out of the nucleus, it binds directly to AGO2, which cleaves it into a mature miRNA duplex.

All miRNA biogenesis pathways converge at the point where the mature miRNA duplex is loaded onto AGO2, which is a part of the RNA-Induced Silencing Complex (RISC). The guide strand is then separated from the passenger strand (miRNA*), which is then degraded; the selected strand determines the specificity for the downstream silencing target [32]. The $5^{\prime}$ nucleotide of each strand (with a preference for adenosine) and the thermodynamic stability of the duplex ends determine which strand becomes the guide strand [33]. The identification of mRNA targets of RISC occurs primarily by complementary base pairing between the $5^{\prime}$ seed region of the guide miRNA (nucleotides 2-8) and the $3^{\prime}$ untranslated region ( $3^{\prime}$ UTR) of the mRNA [34]. The mechanism of silencing of mRNA depends on the extent of base pairing between the seed region and the target mRNA sequence; exact matches result in cleavage of the mRNA by AGO2, while partial matches result in translation repression [27].

The above description makes it clear how the structure of the matured miRNAs use the mechanisms to target and repress mRNAs of specific genes for affecting intracellular signaling pathways. A recent study showed that increasing the expression of a specific miRNA could target and repress the mRNA of the mechanistic target of rapamycin (mTOR), an 
inhibitor of autophagy, to sustain neuroprotective autophagy and promote motor function recovery in SCI [35]. In this study, investigators increased the level of miR-421-3p that could bind to the 3' UTR of mTOR to significantly reduce mTOR activity and increase autophagy and decrease neuronal apoptosis in SCI mice. Further, treatment with an miR-421-3p inhibitor showed a decrease in neuroprotective autophagy in SCI mice.

\section{Components of the Autophagy Pathway from Nucleation to Fusion}

We are somewhat tersely describing different components of the complex autophagy pathway for an appreciation of its mechanism for a neuroprotective role in SCI. The autophagy pathway is divided into four phases: nucleation (or induction) of the phagophore, elongation of the phagophore, maturation of the autophagosome, and fusion of autophagosome with a lysosome to form an autolysosome. Regulation of autophagy flux in SCI depends on the spatiotemporally precise activity of numerous ATG proteins. Initiation of the nucleation phase depends on the recruitment and activation of two protein complexes: the Unc-51-like autophagy activating kinase (ULK) complex and the class III phosphatidylinositol-3-kinase complex (PIK3C3) [4,36].

The ULK complex is comprised of Unc-51-like serine/threonine kinases 1 and 2 (ULK1 and ULK2 $[37,38])$, the focal adhesion kinase (FAK) family kinase-interacting protein of $200 \mathrm{kDa}$ (FIP200), ATG13, and ATG101. The ULK complex acts as a gatekeeper for the autophagy pathway; it receives information about the status of the cell from its upstream regulators - most significantly, the mTOR complex 1 (mTORC1) and AMPK-and modulates the autophagy flux accordingly [39].

AMPK is an important sensor of metabolic stress in the cell, and it acts to inhibit and activate numerous anabolic and catabolic pathways, respectively. In addition to the "canonical" activation of AMPK due to phosphorylation by the tumor suppressor liver kinase B1 (LKB1) and increase in the AMP levels, AMPK may also be activated by other indicators of cellular stress, such as glucose starvation and $\mathrm{Ca}^{2+}$ release from endoplasmic reticulum (ER), leading to AMPK phosphorylation [40]. Subsequently, AMPK phosphorylates proteins associated with the cell growth-cell survival axis (including the ULK complex), resulting in an increase in catabolic processes to provide the cell with the resources needed to adapt to changing conditions [41]. Thus, AMPK acts as an activator of the ULK complex and positively regulates autophagy.

The serine/threonine protein kinase mTOR forms two protein complexes: mTORC1 and mTORC2. mTORC1 is a complex of the mTOR catalytic subunit, Raptor (regulatoryassociated protein of mammalian target of rapamycin; necessary for proper localization of the complex to the lysosomal surface and recognition of some substrates [42,43]), PRAS40 (Proline-Rich Akt Substrate of $40 \mathrm{kDa}$ ), DEPTOR (DEP domain containing the mTORinteracting protein), the Tti1/Tel2 complex, and mLST8 (mammalian Lethal with SEC13 protein 8) [44]. mTORC1 is activated in response to increases in the cellular nutrient and energy levels $[40,45]$. Activated mTORC1 facilitates cell growth by upregulating anabolic processes such as protein and lipid biosynthesis and by downregulating catabolic processes like autophagy via phosphorylation of the ULK complex [46].

AMPK also regulates mTORC1. The inhibition of mTORC1 by AMPK is achieved by direct phosphorylation of the Raptor subunit of mTORC1, as well as by phosphorylation of the tuberous sclerosis complexes (TSC) 1 and 2 (TSC1/2), which are GTPase-activating proteins (GAP) affecting the Rheb-GTP complex, an activator of mTORC1 [44,47]. Additionally, mTORC1 inhibits the nuclear localization of TFEB (Transcription Factor EB) and TFE3 (Transcription Factor binding to IGHM Enhancer 3), translation factors promoting lysosome biogenesis and autophagy, while AMPK activity is necessary for the activation of those same factors $[48,49]$. Furthermore, the interactions between AMPK/mTORC1 and the ULK complex are not unidirectional. ULK1 can phosphorylate and inhibit both mTORC1 and AMPK, resulting in seemingly contradictory positive and negative feedback loops, respectively [50-52]. 
The earliest event in the nucleation of the phagophore is generally considered to be the recruitment of the ULK complex to a nascent nucleation site on the ER (Figure 4). The ATG9A-vesicle-mediated incorporation of PtdIns(4)P (phosphatidylinositol-4-phosphate) into the ER membrane by PI4K III $\beta$ (phosphatidylinositol-4-kinase III beta) facilitates binding of the ULK complex to the nucleation site [53,54]. The ULK complex then activates PIKC3C, which subsequently enriches the ER membrane with PtdIns(3)P (phosphatidylinositol3-phosphate), leading to the formation of a cup-shaped ER subdomain known as an omegasome $[55,56]$. The formation of omegasomes and subsequently autophagosomes has been shown to be associated with MCS (membrane contact sites), the most well-described being the ER-phagophore and ER-mitochondria contact sites (as in mitophagy) [57-59].

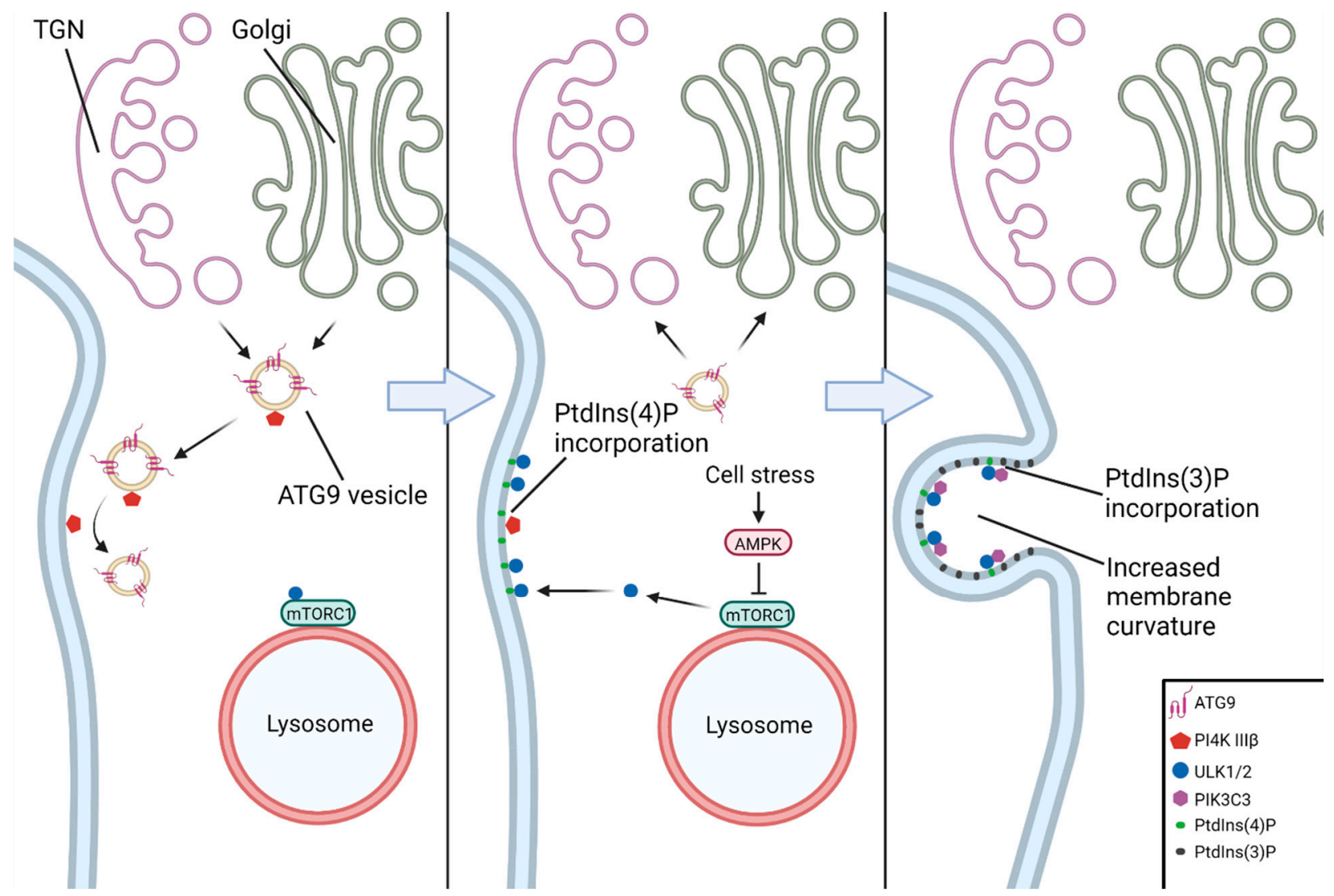

Figure 4. A model of formation of the omegasome. ATG9 vesicles carry PI4K III $\beta$ from the Golgi and trans-Golgi network to the omegasome formation site. PI4K III $\beta$ enriches the ER membrane in PtdIns(4)P, which binds ULK1/2 after its AMPK-mediated release from mTORC1 at the lysosomal surface. ULK1/2 subsequently recruits PIKC3C, which enriches the ER membrane in PtdIns(3)P, resulting in increased membrane curvature. As more PtdIns(3)P is incorporated, the highly curved membrane forms the omegasome, where the phagophore may be nucleated.

The beginning of the elongation phase is marked by the recruitment of members of the WIPI (WD-repeat domain phosphoinositide-interacting protein) family of proteins to the nascent phagophore (Figure 5). All four of the WIPI proteins (WIPI1-4) involved in the autophagy pathway are effectors of the PtdIns(3)P produced by PIKC $3 \mathrm{C}$ at the omegasome [60]. WIPI1 and WIPI2 are the first to associate with the phagophore, and while not strictly necessary for autophagy, WIPI1 has been shown to associate with and enhance the action of WIPI2 [61]. WIPI2 subsequently recruits the ATG12-ATG5ATG16L1 complex, which is necessary for the lipidation of LC3 (microtubule-associated protein Light Chain 3)/GABARAP (GABA type A Receptor-Associated Protein) family proteins to the inner and outer autophagosomal membranes [62-64]. LC3 lipidation is 
accomplished through a ubiquitin-like conjugation system. Pro-LC3/pro-GABARAP in the cytosol is cleaved by ATG4 to form LC3-I/GABARAP-I, which is then activated by and transferred to ATG7 (E1-like) and subsequently transferred to ATG3 (E2-like). Finally, the ATG12-ATG5-ATG16L1 (E3-like) complex promotes the conjugation of LC3I/GABARAP-I to PE (phosphatidylethanolamine) in the autophagosomal membrane to form LC3-II/GABARAP-II [65]. The LC3-II/GABARAP-II family proteins are crucial for autophagosomal growth and closure, cargo targeting through adaptor proteins such as sequestosome 1 (SQSTM1)/p62 (in selective autophagy), and maturation [66]. LC3-II is a reliable marker of autophagosome formation.

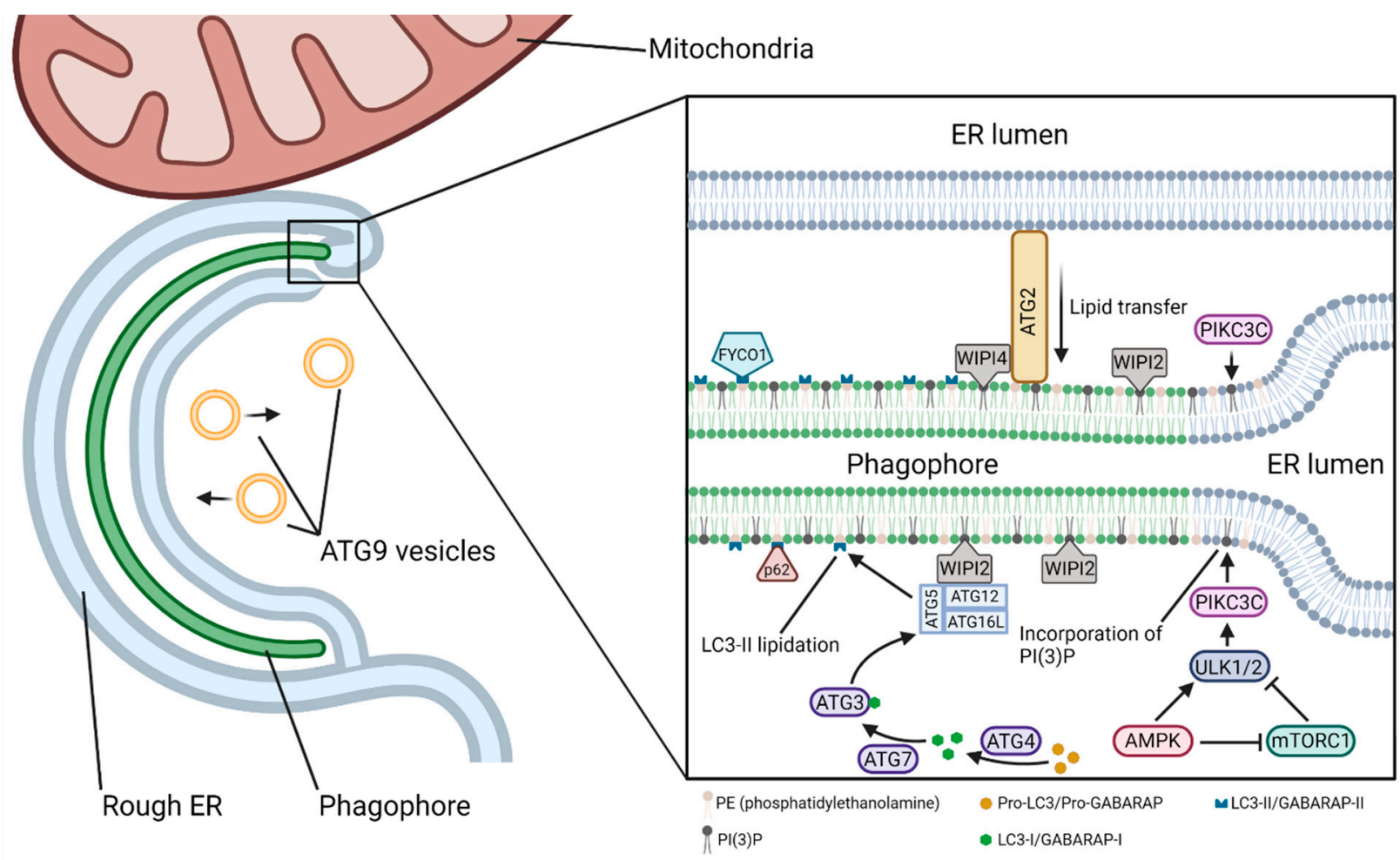

Figure 5. Elongation of the phagophore. WIPI proteins are recruited to the phagophore membrane by PtdIns(3)P, where they act as an adaptor for a variety of proteins that shape and modify the phagophore. The membrane sources that feed the growing phagophore can be varied. Direct extrusion of the ER or other membranes may contribute to phagophore growth. Additionally, ATG2 may transfer lipids from one membrane to another, such as from the ER or ATG9 vesicles (not shown). ATG9 vesicles may also donate lipids through a kiss-and-run mechanism, though no ATG9 proteins are transferred to the phagophore. Pro-LC3 in the cytosol is converted by ATG4 into LC3-I, which is transported to ATG3 by ATG7. ATG3 brings LC3-I to the ATG12-ATG5-ATG16L1 complex, which processes it into LC3-II and conjugates it to PE (phosphatidylethanolamine) in the phagophore membrane. LC3-II then acts as an adaptor for various effector proteins.

Growing phagophores are continuous or closely associated with membranes of the ER, Golgi complex (GC), recycling and late endosomes (LEs), lysosomes, mitochondria, and plasma membrane, as well as lipid droplets $[58,67,68]$. The ER, which is in contact with both the inner and outer surfaces of the phagophore [69,70], along with the mitochondria, can act as the primary suppliers of lipids to the phagophore, whether by membrane extrusion or the direct movement of lipids across lipid-transfer proteins such as the ATG2-WIPI4-ATG9 complex [71,72]. Though the ER acts as an inexhaustible lipid pool, phagophore-localized de novo production of lipids by ER-resident lipid synthesis proteins is a significant contributor to phagophore expansion [73,74]. ERGIC (ER-Golgi intermediate compartment)-derived COPII (cytoplasmic coat protein complex II) vesicles and recycling endosome-derived 
vesicles positive for ATG9 and ATG16L1 contribute to, or even serve as the platform for, phagophore initiation and/or growth [4,53,75-78].

Phagophore at an appropriate size must be sealed to form an autophagosome. The sealing is facilitated by the ESCRT (endosomal-sorting complexes required for transport) machinery (consisting of protein complexes ESCRT-0 through ESCRT-III). Of these, only ESCRT-III is strictly necessary to produce the sealed autophagosomes, though the autophagic flux is hindered in the absence of ESCRT-0, ESCRT-I, and ESCRT-II [79-83]. Recruitment of the ESCRT machinery to unsealed phagophores may follow the canonical pathway [83] or an alternate pathway, as in yeast [84]. The closure is completed when ESCRT machinery is disassembled by the VPS4 (vacuolar protein sorting 4) complex.

Autophagosome maturation necessitates the removal of ATG proteins from the outer membrane, primarily by cleavage/delipidation of ATG8 members by the ATG4 family of proteases but also potentially by the activity of PtdIns(3)P phosphatases [85-87]. An autophagosome undergoes fusion with a lysosome to form an autolysosome, where lysosomal hydrolases degrade the inner autophagosomal membrane and its contents into basic units (amino acids, nucleotides, etc.) to be reused by the cell. Before fusion with a lysosome, mature autophagosomes may fuse with early and/or late endosomes (LEs) to form amphisomes, and there is evidence that this may, in fact, be required for fusion with lysosomes $[87,88]$. The fusion of autophagosomes with lysosomes/LEs involves several SNARE (Soluble N-ethylmaleimide-sensitive factor Attachment protein REceptor) complexes, motor proteins, tether complexes, Rab GTPases, and their GEFs (guanine nucleotide exchange factors). To begin with, the autophagosomes must be brought into contact with lysosomes, which are localized near the nucleus under starvation [89]. The positioning of autophagosomes and lysosomes (and the resulting autophagic flux) is influenced by interactions with the motor proteins dynein and kinesin, which are mediated by PtdIns(3)P, ATG8 members, and RAB7 (RAs-related in Brain protein 7, a member of small GTPases) in autophagosomes and ARL8 (ARf-Like protein 8), BORC ((BLOC-One-Related Complex), RILP (Rab Interacting Lysosomal Protein), RAB7, ORP1L (oxysterol-binding protein or OSBP-Related Protein 1L), and others in (auto)lysosomes [87,89-91].

Subsequently, tether complexes link the two membranes for fusion by binding PtdIns(3)P, ATG8 members, components of the SNARE complex, and/or RAB7 or its effectors. The primary contributor is the HOPS (HOmotypic fusion and vacuole Protein Sorting) complex, though EPG5 (Ectopic P-Granules autophagy protein 5 homolog), ATG14L, and BRUCE (Baculovirus IAP Repeat-containing Ubiquitin-Conjugating Enzyme) may play roles in fusion $[92,93]$. The tethering factors promote the recruitment of autophagyassociated SNARE complexes, of which there are two in humans: the YKT6 (vesicular SNARE homolog)-SNAP29 (SyNaptosomal-Associated Protein 29)-STX7 (SynTaXin 7) complex and the STX17-SNAP29-VAMP7 / 8 (Vesicle-Associated Membrane Proteins 7 and 8) complex [94,95]. Additionally, there is evidence that STX16 plays a role in fusion [96]. Fusion releases the inner autophagosomal membrane and its contents into the interior of the lysosome, where they are degraded by acid hydrolases and released into the cytosol for recycling and cell survival.

Recent studies show the important roles of some specific miRNAs in the suppression of selective mRNAs for the promotion of autophagy and inhibition of apoptosis, providing us unique therapeutic opportunities for neuroprotection and functional recovery in many preclinical models of SCI $[97,98]$. The therapeutic use of specific miRNAs for the promotion of protective autophagy is likely to inhibit inflammation and neuropathic pain, prevent apoptosis in neurons and glial cells, and contribute to axonal regeneration mostly in the remote regions of the central nervous system (CNS) injuries [97-99].

\section{Specific miRNAs in Modulation of Autophagy in Preclinical Models of SCI}

Autophagy at the basal levels is generally understood as promoting cell survival, but under certain conditions, changes in the autophagy flux or blockage of the autophagy pathway can promote cell death. Autophagy-dependent cell death in a strict sense appears 
to be a highly specific process primarily occurring during early development [100]. What occurs in many pathophysiological conditions like SCI is more accurately called autophagyassociated or autophagy-mediated cell death, wherein changes in the autophagy flux accompany and interact with the activation of other cell death pathways such as apoptosis. The crosstalk between autophagy and apoptosis is complex and an area of active research. There are several enlightening review papers already published on the subject [101-103]; however, some of the different ways autophagy and cell death are related will be briefly covered here for some context.

A buildup of autophagosomal bodies in cells has been shown to precede apoptosis in neurons and other cells [101,102,104]. Such a buildup may be the result of an increased production of autophagosomes and/or inhibition of autophagosome clearance. There is evidence that autophagosomal membranes act as scaffolds for the assembly of pro-apoptotic and pro-necrotic protein complexes [101]. An increased number of autophagosomes may therefore induce cell death by promoting the formation of these complexes. Defective autophagy can lead to the accumulation of protein aggregates as well as of damaged mitochondria, which subsequently can cause mitochondrial release of cytochrome c into the cytosol to initiate apoptosis [105]. Several ATG proteins are known to become proapoptotic factors when cleaved by calpain (ATG5) or caspases (ATG4 and Beclin 1) [101,102]. Selective autophagy may target either pro-death or pro-survival factors to influence the fate of a cell $[106,107]$. The exact nature of the interactions among the autophagy, apoptosis, and necrosis that determine cell death or survival are still not well understood.

Apoptotic activity following SCI varies significantly depending on the type and severity of the injury, as well as over the phases of SCI recovery $[9,108]$. However, a consistent difficulty in assessing the overall efficacy of autophagy activation/inhibition at a given phase in SCI recovery results from a lack of consensus in the literature on the results of autophagy activation or inhibition in a given injury context; a recent meta-analysis demonstrated that SCI recovery is improved by the modulation of autophagy but shows no significant difference in the Basso, Beattie, and Bresnahan (BBB) locomotor scores between upregulation and downregulation in mouse injury models [109]. In the previously referenced meta-analysis, the 33 included studies generally achieved a modulation of autophagy in SCI by chemical means (e.g., rapamycin and metformin) rather than via miRNAs. In comparison, the number of studies examining the modulation of autophagy in SCI by miRNAs specifically is small, and to the authors' knowledge, no comparable meta-analysis exists. Notably, there is a lack of studies in the literature examining the miRNA-mediated upregulation of autophagy in SCI (miR-15a is the sole miRNA with sufficient previous research to be included in our review that caused an increase in autophagy flux). As previously noted, the complexity and sensitivity of autophagy regulation pathways and the double-edged nature of autophagy's relation to cell death suggest that this inconsistency in results may be due to small differences in the experimental procedure, and further research is needed to elucidate the points at which the neuroprotective or neurodegenerative properties of autophagy dominate (Figure 6). The effort toward full elucidation of the autophagy's role in SCI across various injury types and phases might benefit from more standardized research methodologies regarding injury type and how long after the primary injury the intervention occurs. Due to the highly dynamic characteristics of SCI, comparisons of the results that arise from experimental conditions that are not highly similar are of limited value. Increased collaboration between research groups in the field to develop standardized methodologies to allow more meaningful comparisons of results could help resolve some of the seemingly conflicting conclusions so far obtained. 


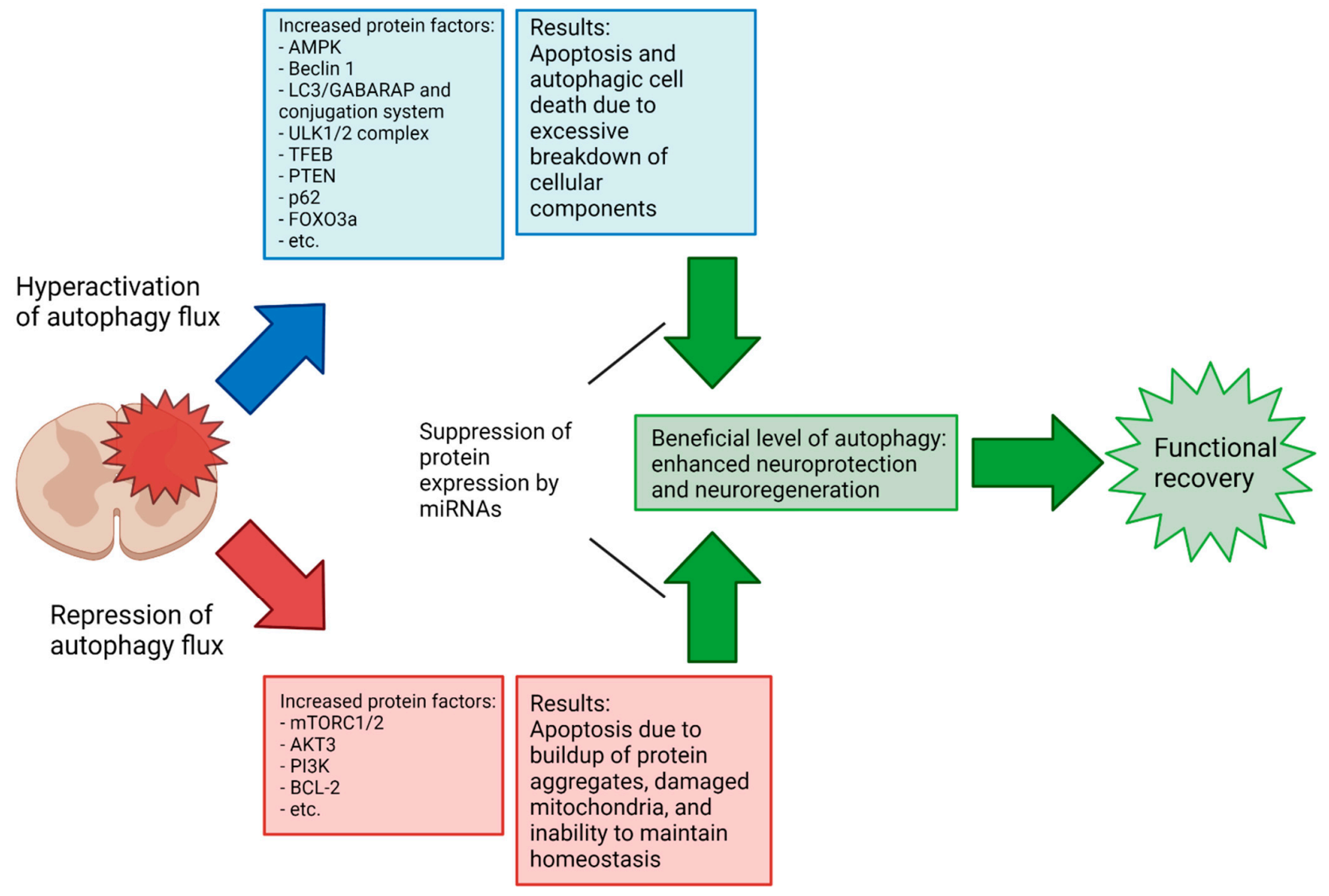

Figure 6. Potential role of miRNAs in promoting functional recovery in SCI. Autophagy may be hyperactivated or repressed to non-optimal levels at a given phase of the SCI secondary injury, leading to poorer recovery or even itself causing deleterious effects. An understanding of the effects that autophagy has on different SCI types and at different phases of secondary injury will be vital to developing effective therapies.

With that in mind, the following sections will explore the relationship between autophagy and SCI, with a particular focus on specific miRNAs that may modulate these interactions for neuroprotection in preclinical models of the SCI (Table 1). Most of the investigations in this field are currently focused on the fine tuning of interactions between specific miRNAs and the molecular components of autophagy, as we described above, to regulate the autophagy flux for functional neuroprotection in preclinical models of SCI with a hope to apply this approach to the SCI patients as soon as possible.

\subsection{Autophagy in Neurons}

Neuronal autophagy is critical for homeostasis in the CNS, as neurons are post-mitotic and therefore limited in their ability to deal with cellular waste. Additionally, their unique morphology creates the requirement for specialized autophagy processes not found in other cell types. Autophagosome formation is constitutively activated not just in the soma but occurs as far as the axon terminal, allowing for a rapid autophagy response along the axon [110]. Degradation of the autolysosomal contents takes place primarily in the soma, necessitating that the kinesin/dynein-mediated anterograde movement of lysosomes and retrograde movements of autophagosomes and autolysosomes along the cytoskeleton be tightly regulated due to the long distances involved [111,112]. The movement of autophagosomes through the axon appears to be strictly unidirectional; somatic autophagosomes are barred from entering the axon [113]. Finally, the LC3-II levels in neurons are relatively low in basal conditions; whether this indicates an innately lower rate of autophagosome formation or a more rapid flux rate in neurons is currently unclear [114]. 
Table 1. Specific miRNAs in modulating autophagy with prospect of influencing SCI recovery.

\begin{tabular}{|c|c|c|c|c|}
\hline microRNA & $\begin{array}{l}\text { Molecular } \\
\text { Target(s) }\end{array}$ & $\begin{array}{c}\text { Effect on } \\
\text { Autophagy Flux }\end{array}$ & $\begin{array}{c}\text { Prospect of SCI } \\
\text { Recovery }\end{array}$ & References \\
\hline miR-93-5p & $\begin{array}{l}\text { PTEN } \\
\text { ATG7 } \\
\text { TLR4 }\end{array}$ & Decrease & Beneficial & [115-117] \\
\hline miR-384-5p & $\begin{array}{l}\text { Beclin } 1 \\
\text { GRP78 }\end{array}$ & Decrease & Beneficial & {$[118,119]$} \\
\hline $\operatorname{miR}-378$ & $\begin{array}{l}\text { ATG12 } \\
\text { GRB2 }\end{array}$ & $\begin{array}{c}\text { Tissue } \\
\text { dependent }\end{array}$ & Beneficial & [120-123] \\
\hline $\operatorname{miR}-27 a$ & $\begin{array}{c}\text { FOXO3a } \\
\text { DRAM2 } \\
\text { PINK1 }\end{array}$ & Decrease & Beneficial & [124-127] \\
\hline $\mathrm{miR}-223$ & RPH1/KDM4A & Decrease & Beneficial & {$[128,129]$} \\
\hline miR-124 & $\begin{array}{c}\text { PI3K } \\
\text { AMPK } \\
\text { Bcl-2 } \\
\text { p62 }\end{array}$ & Decrease & Beneficial & [130-132] \\
\hline miR-212-3p & PTEN & Decrease & Beneficial & [133-136] \\
\hline miR-15a & $\begin{array}{l}\text { Akt3 } \\
\text { Rictor }\end{array}$ & Increase & $\begin{array}{c}\text { Beneficial (in } \\
\text { neuropathic pain model) }\end{array}$ & {$[137,138]$} \\
\hline miR-384-5p & Beclin 1 & Decrease & Beneficial & [139] \\
\hline $\operatorname{miR}-223$ & $\begin{array}{l}\text { FOXO3a } \\
\text { ATG16L }\end{array}$ & Decrease & Beneficial & [140-144] \\
\hline miR-30 & Beclin 1 & $\begin{array}{c}\text { Tissue } \\
\text { dependent }\end{array}$ & Context dependent & [145-149] \\
\hline miR-30d & Beclin 1 & $\begin{array}{l}\text { Increase or } \\
\text { decrease }\end{array}$ & Beneficial & [150-152] \\
\hline
\end{tabular}

In rat retinal ganglion neurons, miR-93-5p was found to reduce autophagy-associated cell death after N-methyl-D-aspartate (NMDA)-induced excitotoxicity by downregulating the expression of phosphatase and tensin homolog (PTEN), which negatively regulates autophagy through the Akt/mTOR pathway [115]. ATG7 and Toll-like receptor 4 (TLR4, an inducer of neuronal autophagy and neuroinflammation [116]) have also been demonstrated to be targets of miR-93-5p, as the overexpression of miR-93-5p results in significantly reduced levels of those proteins, with an accompanying reduction in autophagy and inflammatory factors and increase in cell survival in rat myocardial tissue [117].

miR-384-5p is one of several miRNAs that target the expression of Beclin 1 (an inducer of autophagy), which contributes to functionality of the PI3K complex [118]. The suppression of Beclin 1 therefore halts autophagy at the point of PtdIns(3)P enrichment and prevents phagophore elongation. Specifically, the application of miR-384-5p was shown to significantly improve the BBB locomotor scores in rats with spinal cord compression injuries after 7 days and 21 days as compared to untreated rats [119]. The same study also reported that inhibition of ER stress via decreasing levels of glucose-regulating protein 78 (GRP78), an ER stress response-mediating protein that is also targeted by miR-384-5p, may have contributed to the lower level of autophagy seen in the study [119].

It has been demonstrated that miR-378 regulates the expression of several ATG proteins and appears to have a promising prospect for the modulation of autophagy in neurons. A report indicated that miR-378 negatively regulated ATG12 expression in rat neurons and reduced apoptosis when administered immediately after contusion SCI, with a corresponding improvement of the BBB locomotor scores 7 days post-injury compared to the sham group, though the study did not identify whether the improvement was necessarily 
due to autophagy impairment [120]. Studies on the long noncoding RNA (lncRNA)-based inhibition of miR-378 revealed that it acts to inhibit autophagy by targeting growth factor receptor-bound protein 2 (GRB2) and ATG12 [121,122]. Alternatively, one study has found that miR-378 activates autophagy in skeletal muscle, indicating that further research into how miR-378 functions in different cell types and what conditions are necessary [123].

Multiple studies have implicated miR-27a in modulating neurodegenerative processes through the modulation of autophagy. It has been reported that the overexpression of miR-27a downregulates autophagy in neurons and inhibits neurodegeneration by targeting FOXO3a (Forkhead bOX O3a, a transcription factor that promotes autophagy [124]) in mouse neurons after a traumatic brain injury [125]. Another study found that miR27a also targets damage-regulated autophagy modulator 2 (DRAM2) and that the rnocircRNA_010705 (circLrp1b)-mediated repression of miR-27a can increase autophagyassociated neurodegeneration [126]. Additionally, miR-27a has been shown to downregulate mitophagy in HeLa cells by targeting PTEN-induced kinase 1 (PINK1), which is a mitochondrial serine/threonine kinase, to suggest that it may protect cells from excessive mitochondria loss in hyper-autophagic conditions [127].

RPH1 (Repressor of PHR1)/KDM4A (lysine- or K-specific DeMethylase 4A) is a DNAbinding protein that acts as a histone demethylase and negatively regulates the transcription of several ATG genes. It has been reported that miR-223 targets RPH1/KDM4A, subsequently reducing the autophagy levels in lipopolysaccharide-treated neuronal PC-12 cells and attenuating cell death [128]. Another study reported that, in yeast, RPH1/KDM4A acted as an autophagy inhibitor under nutrient-rich conditions and did not show any effect on translation in nitrogen-starved conditions [129]. Clearly, more research is necessary to clarify the functions of RPH1/KDM4A, specifically in mammalian cells, to rectify this difference.

The expression of miR-124, a key miRNA in neural development, has been linked to regulation of the autophagy pathway via its regulation of the Akt/AMPK/mTOR axis [130]. However, as in many other cases involving autophagy, there is conflicting evidence as to whether its overexpression or under-expression bestows neuroprotective and/or neuroregenerative effects in the spinal cord specifically. A study found that antagomiR-124 had a neuroprotective effect when introduced 5 days before spinal cord ischemia-reperfusion injury in rats, with a reduction in apoptosis and increase in the levels of mitochondrial LC3-II and Beclin 1, causing an increase in neuronal mitophagy [131]. Conversely, another report showed that antagomiR-124 administered $24 \mathrm{~h}$ before cerebral ischemia-reperfusion injury produces a neuroprotective effect by promoting the PI3K/Akt/mTOR pathway, with rats exhibiting an increase in the PI3K/Akt/mTOR levels and improvement in neurological function, in part, due to downregulation of autophagy by the PI3K/Akt/mTOR pathway [132]. To reconcile these conclusions, it should be noted that these studies involved neural tissue in different locations and quantified different proteins (PI3K/Akt/mTOR function upstream of LC3-II and Beclin 1 in the autophagy pathway) in different cell fractions (the whole cell vs. mitochondria). The conflicting results from these studies underline the need for more thorough research into the function of this specific miR-124 as it relates to pathophysiology of SCI before any potential therapy utilizing it is developed.

In a recent study, miR-212-3p has been shown to have a positive effect on recovery from SCI in rats [133]. PTEN is a possible target of miR-212-3p, and it is demonstrated that the silencing of PTEN may be the reason behind the improvement in the recovery in SCI rats treated with miR-212-3p. The molecular mechanism involved in this recovery process seems so far convincing. The silencing of PTEN leads to the activation of Akt and mTOR, suggesting that the beneficial effects of miR-212-3p may be due to the inhibition of autophagy. Indeed, other studies have linked miR-212-3p to autophagy regulation in cardiomyocytes, osteosarcoma cells, and prostate cancer cells [134-136]. However, it has yet to be conclusively shown that the neuroprotective effects of miR-212-3p in SCI are due to autophagy inhibition. 


\subsection{Autophagy in Glial Cells}

A study shows that miR-15a positively regulates autophagy in rat microglial cells by reducing the Akt3 levels and increasing the expression of ATG proteins [137]. In addition, another study showed that miR-15a and miR-16 promote autophagy in HeLa cells by targeting the Rictor subunit of mTORC2, an upstream activator of Akt3 [138].

In addition to the previously mentioned role of miR-384-5p beneficially downregulating autophagy in neurons, there is evidence that it has anti-inflammatory effects in the brain through the inhibition of autophagy in macrophages [139]. The pro-inflammatory effects of autophagy in this case may be due to autophagy leading to an increase in the macrophage cell viability, which is negated by suppression of autophagy promoter Beclin 1 by overexpression of miR-384-5p that binds to 3' UTR of Beclin 1 mRNA [139]. If so, this would highlight one of the ways that the modulation of autophagy in each direction might have significantly different effects (e.g., cell survival vs. cell death) in different cell types, including those that might be closely associated in the context of a particular injury.

As previously mentioned for its role in neural autophagy, miR-223 has also been implicated in reducing neuroinflammation in microglia by targeting ATG16L $[140,141]$. Interestingly, it has been found that FOXO3a is yet another autophagy-related target of miR-223, with a negative correlation between the miR-223 levels and FOXO3a expression reported in several cell types [142-144].

Various studies have clearly indicated that Beclin 1 in the CNS tissues is a potential target of several members of the miR-30 family [145-149]. Of these, the effects of miR-30d are the best characterized in relation to SCI. AntagomiRs of miR-30d promoted autophagy and reduced apoptosis in post-ischemia astrocytes [150] and neonatal rat neurons [151], while another study demonstrated that miR-30d decreased neuroinflammation by reducing autophagy in macrophages and subsequently promoting M2 macrophage polarization over M1 [152]. Additionally, the sponging of miR-30b and miR-30d by lncRNAs SNHG12 (small nucleolar RNA host gene 12) and C2dat2 (CAMK2D-associated transcript 2), respectively, was shown to increase autophagy and apoptosis after cerebral ischemia-reperfusion injury $[146,153]$.

\section{Conclusions}

Autophagy plays a significant role in influencing the pathogenesis and outcomes in SCI, but the current treatments do not address this critical factor, leaving plentiful opportunities to discover novel therapies for a devastating neuropathological condition that affects the lives of many people, who are mostly young individuals. Interest in the involvement and use of specific miRNAs to treat numerous conditions continues to grow, and recent research has identified many miRNAs that may regulate autophagy in the pathophysiological processes in the CNS $[154,155]$. Both miRNAs and autophagy are associated with ER stress, which triggers the unfolded protein response (UPR) to restore normal function of the ER [156]. Future studies therefore need to identify the molecular mechanisms of how specific miRNAs interrupt the UPR for the induction of autophagy under ER stress in SCI. Clearly, many uncertainties remain. The role of autophagy as either a neuroprotective or neurodegenerative factor in the various phases of SCI has not been fully elucidated, with the current studies exhibiting a lack of consensus at any given point. Additionally, while there are numerous studies on the effects of autophagy and its modulation by miRNAs in the CNS, there are relatively few focusing specifically on SCI, which has a unique biomolecular environment. The current investigations indicate that miRNA therapies are an attractive and promising prospect for the treatment of SCI, but a greater understanding of the process of autophagy and its effects in the spinal cord, as well as the further identification of potentially beneficial miRNAs and elucidation of the overall effects of specific miRNAs in the regulation of autophagy in the context of pathophysiology of SCI, will be necessary before any effective therapies can be developed in the future. 


\begin{abstract}
Author Contributions: Conceptualization, R.V. and S.K.R.; methodology, R.V.; resources, R.V.; writing-original draft preparation, R.V.; writing-review and editing, R.V. and S.K.R.; visualization, R.V.; and supervision, S.K.R. All authors have read and agreed to the published version of the manuscript.
\end{abstract}

Funding: This work was supported in part by the earlier R01 grants (CA-091460 and NS-057811) from the National Institutes of Health (Bethesda, MD, USA) and a current SCI grant (SCIRF-2020-PD-01) from the State of South Carolina (Columbia, SC, USA).

Institutional Review Board Statement: It is not relevant to this work.

Informed Consent Statement: It is not applicable.

Data Availability Statement: It is not applicable.

Acknowledgments: All figures were created with BioRender.com (accessed in December 2021).

Conflicts of Interest: The authors declare no conflict of interest.

\title{
References
}

1. Galluzzi, L.; Baehrecke, E.H.; Ballabio, A.; Boya, P.; Bravo-San Pedro, J.M.; Cecconi, F.; Choi, A.M.; Chu, C.T.; Codogno, P.; Colombo, M.I.; et al. Molecular definitions of autophagy and related processes. EMBO J. 2017, 36, 1811-1836. [CrossRef] [PubMed]

2. Reggiori, F.; Klionsky, D.J. Autophagy in the eukaryotic cell. Eukaryot. Cell 2002, 1, 11-21. [CrossRef] [PubMed]

3. Klionsky, D.J.; Cregg, J.M.; Dunn, W.A., Jr.; Emr, S.D.; Sakai, Y.; Sandoval, I.V.; Sibirny, A.; Subramani, S.; Thumm, M.; Veenhuis, M.; et al. A unified nomenclature for yeast autophagy-related genes. Dev. Cell 2003, 5, 539-545. [CrossRef]

4. Melia, T.J.; Lystad, A.H.; Simonsen, A. Autophagosome biogenesis: From membrane growth to closure. J. Cell Biol. 2020, 219, e202002085. [CrossRef] [PubMed]

5. Antonioli, M.; Di Rienzo, M.; Piacentini, M.; Fimia, G.M. Emerging mechanisms in initiating and terminating autophagy. Trends Biochem. Sci. 2017, 42, 28-41. [CrossRef]

6. Li, L.; Tan, J.; Miao, Y.; Lei, P.; Zhang, Q. ROS and autophagy: Interactions and molecular regulatory mechanisms. Cell Mol. Neurobiol. 2015, 35, 615-621. [CrossRef]

7. Mizushima, N.; Levine, B. Autophagy in human diseases. N. Engl. J. Med. 2020, 383, 1564-1576. [CrossRef]

8. Chu, C.T. Mechanisms of selective autophagy and mitophagy: Implications for neurodegenerative diseases. Neurobiol. Dis. 2019, 122, 23-34. [CrossRef]

9. Zhou, K.; Sansur, C.A.; Xu, H.; Jia, X. The temporal pattern, flux, and function of autophagy in spinal cord injury. Int. J. Mol. Sci. 2017, 18, 466. [CrossRef]

10. Lo, J.; Chan, L.; Flynn, S. A systematic review of the incidence, prevalence, costs, and activity and work limitations of amputation, osteoarthritis, rheumatoid arthritis, back pain, multiple sclerosis, spinal cord injury, stroke, and traumatic brain injury in the United States: A 2019 update. Arch. Phys. Med. Rehabil. 2021, 102, 115-131.

11. Khorasanizadeh, M.; Yousefifard, M.; Eskian, M.; Lu, Y.; Chalangari, M.; Harrop, J.S.; Jazayeri, S.B.; Seyedpour, S.; Khodaei, B.; Hosseini, M.; et al. Neurological recovery following traumatic spinal cord injury: A systematic review and meta-analysis. J. Neurosurg. Spine 2019, 130, 683-699. [CrossRef] [PubMed]

12. Ahuja, C.S.; Wilson, J.R.; Nori, S.; Kotter, M.R.N.; Druschel, C.; Curt, A.; Fehlings, M.G. Traumatic spinal cord injury. Nat. Rev. Dis. Primers 2017, 3, 17018. [CrossRef] [PubMed]

13. Flack, J.A.; Sharma, K.D.; Xie, J.Y. Delving into the recent advancements of spinal cord injury treatment: A review of recent progress. Neural Regen. Res. 2022, 17, 283-291. [PubMed]

14. Hejrati, N.; Fehlings, M.G. A review of emerging neuroprotective and neuroregenerative therapies in traumatic spinal cord injury. Curr. Opin. Pharmacol. 2021, 60, 331-340. [CrossRef]

15. Alizadeh, A.; Dyck, S.M.; Karimi-Abdolrezaee, S. Traumatic spinal cord injury: An overview of pathophysiology, models and acute injury mechanisms. Front. Neurol. 2019, 10, 282. [CrossRef]

16. Ahuja, C.S.; Nori, S.; Tetreault, L.; Wilson, J.; Kwon, B.; Harrop, J.; Choi, D.; Fehlings, M.G. Traumatic spinal cord injury-repair and regeneration. Neurosurgery 2017, 80, S9-S22. [CrossRef]

17. Anjum, A.; Yazid, M.D.; Fauzi Daud, M.; Idris, J.; Ng, A.M.H.; Selvi Naicker, A.; Ismail, O.H.R.; Kumar, R.K.A.; Lokanathan, Y. Spinal cord injury: Pathophysiology, multimolecular interactions, and underlying recovery mechanisms. Int. J. Mol. Sci. 2020, 21, 7533. [CrossRef]

18. Hayta, E.; Elden, H. Acute spinal cord injury: A review of pathophysiology and potential of non-steroidal anti-inflammatory drugs for pharmacological intervention. J. Chem. Neuroanat. 2018, 87, 25-31. [CrossRef]

19. Tran, A.P.; Warren, P.M.; Silver, J. The biology of regeneration failure and success after spinal cord injury. Physiol. Rev. 2018, 98, 881-917. [CrossRef]

20. Roy, A.; Pathak, Z.; Kumar, H. Strategies to neutralize RhoA/ROCK pathway after spinal cord injury. Exp. Neurol. 2021, 343, 113794. [CrossRef] 
21. Dyck, S.M.; Alizadeh, A.; Santhosh, K.T.; Proulx, E.H.; Wu, C.-L.; Karimi-Abdolrezaee, S. Chondroitin sulfate proteoglycans negatively modulate spinal cord neural precursor cells by signaling through LAR and RPTPo and modulation of the Rho/ROCK pathway. Stem Cells 2015, 33, 2550-2563. [CrossRef] [PubMed]

22. Beck, K.D.; Nguyen, H.X.; Galvan, M.D.; Salazar, D.L.; Woodruff, T.M.; Anderson, A.J. Quantitative analysis of cellular inflammation after traumatic spinal cord injury: Evidence for a multiphasic inflammatory response in the acute to chronic environment. Brain 2010, 133, 433-447. [CrossRef] [PubMed]

23. Wightman, B.; Ha, I.; Ruvkun, G. Posttranscriptional regulation of the heterochronic gene lin-14 by lin-4 mediates temporal pattern formation in C. elegans. Cell 1993, 75, 855-862. [CrossRef]

24. Lee, R.C.; Feinbaumt, R.L.; Ambrost, V. The C. elegans heterochronic gene lin-4 encodes small RNAs with antisense complementarity to lin-14. Cell 1993, 75, 843-854. [CrossRef]

25. Fromm, B.; Domanska, D.; Høye, E.; Ovchinnikov, V.; Kang, W.; Aparicio-Puerta, E.; Johansen, M.; Flatmark, K.; Mathelier, A.; Hovig, E.; et al. MirGeneDB 2.0: The metazoan microRNA complement. Nucleic Acids Res. 2020, 48, D132-D141. [CrossRef]

26. Alles, J.; Fehlmann, T.; Fischer, U.; Backes, C.; Galata, V.; Minet, M.; Hart, M.; Abu-Halima, M.; Grässer, F.A.; Lenhof, H.-P.; et al. An estimate of the total number of true human miRNAs. Nucleic Acids Res. 2019, 47, 3353-3364. [CrossRef]

27. Bartel, D.P. Metazoan microRNAs. Cell 2018, 173, 20-51. [CrossRef]

28. Friedman, R.C.; Farh, K.K.-H.; Burge, C.B.; Bartel, D.P. Most mammalian mRNAs are conserved targets of microRNAs. Genome Res. 2009, 19, 92-105. [CrossRef]

29. Wang, S.; Talukder, A.; Cha, M.; Li, X.; Hu, H. Computational annotation of miRNA transcription start sites. Brief Bioinform. 2021, 22, 380-392. [CrossRef]

30. Nguyen, T.A.; Jo, M.H.; Choi, Y.-G.; Park, J.; Kwon, S.C.; Hohng, S.; Kim, V.N.; Woo, J.-S. Functional anatomy of the human microprocessor. Cell 2015, 161, 1374-1387. [CrossRef]

31. Stavast, C.J.; Erkeland, S.J. The non-canonical aspects of microRNAs: Many roads to gene regulation. Cells 2019, 8, 1465. [CrossRef] [PubMed]

32. Treiber, T.; Treiber, N.; Meister, G. Regulation of microRNA biogenesis and its crosstalk with other cellular pathways. Nat. Rev. Mol. Cell Biol. 2019, 20, 5-20. [CrossRef] [PubMed]

33. Medley, J.C.; Panzade, G.; Zinovyeva, A.Y. microRNA strand selection: Unwinding the rules. Wiley Interdiscip. Rev. RNA 2021, 12, e1627. [CrossRef] [PubMed]

34. Bartel, D.P. microRNAs: Target recognition and regulatory functions. Cell 2009, 136, 215-233. [CrossRef] [PubMed]

35. Wang, J.; Rong, Y.; Ji, C.; Lv, C.; Jiang, D.; Ge, X.; Gong, F.; Tang, P.; Cai, W.; Liu, W.; et al. microRNA-421-3p-abundant small extracellular vesicles derived from M2 bone marrow-derived macrophages attenuate apoptosis and promote motor function recovery via inhibition of mTOR in spinal cord injury. J. Nanobiotechnol. 2020, 18, 72. [CrossRef]

36. Corona Velazquez Angel, F.; Jackson William, T. So many roads: The multifaceted regulation of autophagy induction. Mol. Cell Biol. 2018, 38, e00303-18. [CrossRef]

37. Anwar, T.; Liu, X.; Suntio, T.; Marjamäki, A.; Biazik, J.; Chan, E.Y.W.; Varjosalo, M.; Eskelinen, E.-L. ER-targeted Beclin 1 supports autophagosome biogenesis in the absence of ULK1 and ULK2 kinases. Cells 2019, 8, 475. [CrossRef]

38. McAlpine, F.; Williamson, L.E.; Tooze, S.A.; Chan, E.Y.W. Regulation of nutrient-sensitive autophagy by uncoordinated 51-like kinases 1 and 2. Autophagy 2013, 9, 361-373. [CrossRef]

39. Wang, B.; Kundu, M. Canonical and noncanonical functions of ULK/Atg1. Curr. Opin. Cell Biol. 2017, 45, 47-54. [CrossRef]

40. González, A.; Hall, M.N.; Lin, S.-C.; Hardie, D.G. AMPK and TOR: The Yin and Yang of cellular nutrient sensing and growth control. Cell Metab. 2020, 31, 472-492. [CrossRef]

41. Herzig, S.; Shaw, R.J. AMPK: Guardian of metabolism and mitochondrial homeostasis. Nat. Rev. Mol. Cell Biol. 2018, 19, 121-135. [CrossRef] [PubMed]

42. Rogala, K.B.; Gu, X.; Kedir, J.F.; Abu-Remaileh, M.; Bianchi, L.F.; Bottino, A.M.S.; Dueholm, R.; Niehaus, A.; Overwijn, D.; Fils, A.-C.P.; et al. Structural basis for the docking of mTORC1 on the lysosomal surface. Science 2019, 366, 468-475. [CrossRef] [PubMed]

43. Yonezawa, K.; Tokunaga, C.; Oshiro, N.; Yoshino, K.-I. Raptor, a binding partner of target of rapamycin. Biochem. Biophys. Res. Commun. 2004, 313, 437-441. [CrossRef] [PubMed]

44. Laplante, M.; Sabatini, D.M. mTOR signaling in growth control and disease. Cell 2012, 149, 274-293. [CrossRef] [PubMed]

45. Condon, K.J.; Sabatini, D.M. Nutrient regulation of mTORC1 at a glance. J. Cell Sci. 2019, 132, jcs222570. [CrossRef] [PubMed]

46. Rabanal-Ruiz, Y.; Otten, E.G.; Korolchuk, V.I. mTORC1 as the main gateway to autophagy. Essays Biochem. 2017, 61, 565-584. [PubMed]

47. Van Nostrand, J.L.; Hellberg, K.; Luo, E.-C.; Van Nostrand, E.L.; Dayn, A.; Yu, J.; Shokhirev, M.N.; Dayn, Y.; Yeo, G.W.; Shaw, R.J. AMPK regulation of Raptor and TSC2 mediate metformin effects on transcriptional control of anabolism and inflammation. Genes Dev. 2020, 34, 1330-1344. [CrossRef]

48. Martina, J.A.; Chen, Y.; Gucek, M.; Puertollano, R. MTORC1 functions as a transcriptional regulator of autophagy by preventing nuclear transport of TFEB. Autophagy 2012, 8, 903-914. [CrossRef]

49. Paquette, M.; El-Houjeiri, L.; C Zirden, L.; Puustinen, P.; Blanchette, P.; Jeong, H.; Dejgaard, K.; Siegel, P.M.; Pause, A. AMPKdependent phosphorylation is required for transcriptional activation of TFEB and TFE3. Autophagy 2021, 17, 3957-3975. [CrossRef] 
50. Löffler, A.S.; Alers, S.; Dieterle, A.M.; Keppeler, H.; Franz-Wachtel, M.; Kundu, M.; Campbell, D.G.; Wesselborg, S.; Alessi, D.R.; Stork, B. Ulk1-mediated phosphorylation of AMPK constitutes a negative regulatory feedback loop. Autophagy 2011, 7, 696-706. [CrossRef]

51. Jung, C.H.; Seo, M.; Otto, N.M.; Kim, D.-H. ULK1 inhibits the kinase activity of mTORC1 and cell proliferation. Autophagy 2011, 7, 1212-1221. [CrossRef] [PubMed]

52. Dunlop, E.A.; Hunt, D.K.; Acosta-Jaquez, H.A.; Fingar, D.C.; Tee, A.R. ULK1 inhibits mTORC1 signaling, promotes multisite Raptor phosphorylation and hinders substrate binding. Autophagy 2011, 7, 737-747. [CrossRef] [PubMed]

53. Karanasios, E.; Walker, S.A.; Okkenhaug, H.; Manifava, M.; Hummel, E.; Zimmermann, H.; Ahmed, Q.; Domart, M.; Collinson, L.; Ktistakis, N.T. Autophagy initiation by ULK complex assembly on ER tubulovesicular regions marked by ATG9 vesicles. Nat. Commun. 2016, 7, 12420. [CrossRef] [PubMed]

54. Judith, D.; Jefferies, H.B.J.; Boeing, S.; Frith, D.; Snijders, A.P.; Tooze, S.A. ATG9A shapes the forming autophagosome through Arfaptin 2 and phosphatidylinositol 4-kinase III $\beta$. J. Cell Biol. 2019, 218, 1634-1652. [CrossRef] [PubMed]

55. Karanasios, E.; Stapleton, E.; Manifava, M.; Kaizuka, T.; Mizushima, N.; Walker, S.A.; Ktistakis, N.T. Dynamic association of the ULK1 complex with omegasomes during autophagy induction. J. Cell Sci. 2013, 126, 5224-5238. [CrossRef]

56. Nascimbeni, A.C.; Codogno, P.; Morel, E. Phosphatidylinositol-3-phosphate in the regulation of autophagy membrane dynamics. FEBS J. 2017, 284, 1267-1278. [CrossRef]

57. Chen, Y.-D.; Fang, Y.-T.; Chang, C.-P.; Lin, C.-F.; Hsu, L.-J.; Wu, S.-R.; Chiu, Y.-C.; Anderson, R.; Lin, Y.-S. S100A10 regulates ULK1 localization to ER-mitochondria contact sites in IFN- $\gamma$-triggered autophagy. J. Mol. Biol. 2017, 429, 142-157. [CrossRef]

58. Nascimbeni, A.C.; Giordano, F.; Dupont, N.; Grasso, D.; Vaccaro, M.I.; Codogno, P.; Morel, E. ER-plasma membrane contact sites contribute to autophagosome biogenesis by regulation of local PI3P synthesis. EMBO J. 2017, 36, 2018-2033. [CrossRef]

59. Kohler, V.; Aufschnaiter, A.; Büttner, S. Closing the gap: Membrane contact sites in the regulation of autophagy. Cells 2020, 9, 1184. [CrossRef]

60. Proikas-Cezanne, T.; Takacs, Z.; Dönnes, P.; Kohlbacher, O. WIPI proteins: Essential PtdIns3P effectors at the nascent autophagosome. J. Cell Sci. 2015, 128, 207-217. [CrossRef]

61. Bakula, D.; Müller, A.J.; Zuleger, T.; Takacs, Z.; Franz-Wachtel, M.; Thost, A.-K.; Brigger, D.; Tschan, M.P.; Frickey, T.; Robenek, H.; et al. WIPI3 and WIPI4 $\beta$-propellers are scaffolds for LKB1-AMPK-TSC signalling circuits in the control of autophagy. Nat. Commun. 2017, 8, 15637. [CrossRef] [PubMed]

62. Strong, L.M.; Chang, C.; Riley, J.F.; Boecker, C.A.; Flower, T.G.; Buffalo, C.Z.; Ren, X.; Stavoe, A.K.; Holzbaur, E.L.; Hurley, J.H. Structural basis for membrane recruitment of ATG16L1 by WIPI2 in autophagy. Elife 2021, 10, e70372. [CrossRef] [PubMed]

63. Lystad, A.H.; Simonsen, A. Phosphoinositide-binding proteins in autophagy. FEBS Lett. 2016, 590, 2454-2468. [CrossRef] [PubMed]

64. Polson, H.E.J.; de Lartigue, J.; Rigden, D.J.; Reedijk, M.; Urbé, S.; Clague, M.J.; Tooze, S. Mammalian Atg18 (WIPI2) localizes to omegasome-anchored phagophores and positively regulates LC3 lipidation. Autophagy 2010, 6, 506-522. [CrossRef] [PubMed]

65. Lystad, A.H.; Simonsen, A. Mechanisms and pathophysiological roles of the ATG8 conjugation machinery. Cells 2019, 8, 973. [CrossRef]

66. Johansen, T.; Lamark, T. Selective autophagy: ATG8 family proteins, LIR motifs and cargo receptors. J. Mol. Biol. 2020, 432, 80-103. [CrossRef]

67. Biazik, J.; Ylä-Anttila, P.; Vihinen, H.; Jokitalo, E.; Eskelinen, E.-L. Ultrastructural relationship of the phagophore with surrounding organelles. Autophagy 2015, 11, 439-451. [CrossRef] [PubMed]

68. Dupont, N.; Chauhan, S.; Arko-Mensah, J.; Castillo, E.F.; Masedunskas, A.; Weigert, R.; Robenek, H.; Proikas-Cezanne, T.; Deretic, V. Neutral lipid stores and lipase PNPLA5 contribute to autophagosome biogenesis. Curr. Biol. 2014, 24, 609-620. [CrossRef]

69. Ylä-Anttila, P.; Vihinen, H.; Jokitalo, E.; Eskelinen, E.-L. 3D tomography reveals connections between the phagophore and endoplasmic reticulum. Autophagy 2009, 5, 1180-1185. [CrossRef]

70. Hayashi-Nishino, M.; Fujita, N.; Noda, T.; Yamaguchi, A.; Yoshimori, T.; Yamamoto, A. A subdomain of the endoplasmic reticulum forms a cradle for autophagosome formation. Nat. Cell Biol. 2009, 11, 1433-1437. [CrossRef]

71. Gómez-Sánchez, R.; Rose, J.; Guimarães, R.; Mari, M.; Papinski, D.; Rieter, E.; Geerts, W.J.; Hardenberg, R.; Kraft, C.; Ungermann, C.; et al. Atg9 establishes Atg2-dependent contact sites between the endoplasmic reticulum and phagophores. J. Cell Biol. 2018, 217, 2743-2763. [CrossRef] [PubMed]

72. Hailey, D.W.; Rambold, A.S.; Satpute-Krishnan, P.; Mitra, K.; Sougrat, R.; Kim, P.K.; Lippincott-Schwartz, J. Mitochondria supply membranes for autophagosome biogenesis during starvation. Cell 2010, 141, 656-667. [CrossRef] [PubMed]

73. Schütter, M.; Giavalisco, P.; Brodesser, S.; Graef, M. Local fatty acid channeling into phospholipid synthesis drives phagophore expansion during autophagy. Cell 2020, 180, 135-149.e14. [CrossRef] [PubMed]

74. Andrejeva, G.; Gowan, S.; Lin, G.; Wong, T.; Fong, A.-C.L.; Shamsaei, E.; Parkes, H.G.; Mui, J.; Raynaud, F.; Asad, Y.; et al. De novo phosphatidylcholine synthesis is required for autophagosome membrane formation and maintenance during autophagy. Autophagy 2020, 16, 1044-1060. [CrossRef]

75. Li, Z.; Huang, W.; Wang, W. Multifaceted roles of COPII subunits in autophagy. Biochim. Biophys. Acta Mol. Cell Res. 2020 1867, 118627. [CrossRef] 
76. Staiano, L.; Zappa, F. Hijacking intracellular membranes to feed autophagosomal growth. FEBS Lett. 2019, 593, 3120-3134. [CrossRef]

77. Puri, C.; Vicinanza, M.; Rubinsztein, D.C. Phagophores evolve from recycling endosomes. Autophagy 2018, 14, 1475-1477. [CrossRef]

78. Maeda, S.; Yamamoto, H.; Kinch, L.N.; Garza, C.M.; Takahashi, S.; Otomo, C.; Grishin, N.V.; Forli, S.; Mizushima, N.; Otomo, T. Structure, lipid scrambling activity and role in autophagosome formation of ATG9A. Nat. Struct. Mol. Biol. 2020, 27, $1194-1201$. [CrossRef]

79. Zhen, Y.; Spangenberg, H.; Munson, M.J.; Brech, A.; Schink, K.O.; Tan, K.-W.; Sørensen, V.; Wenzel, E.M.; Radulovic, M.; Engedal, N.; et al. ESCRT-mediated phagophore sealing during mitophagy. Autophagy 2020, 16, 826-841. [CrossRef]

80. Djeddi, A.; Michelet, X.; Culetto, E.; Alberti, A.; Barois, N.; Legouis, R. Induction of autophagy in ESCRT mutants is an adaptive response for cell survival in C. elegans. J. Cell Sci. 2012, 125, 685-694. [CrossRef]

81. Oshima, R.; Hasegawa, T.; Tamai, K.; Sugeno, N.; Yoshida, S.; Kobayashi, J.; Kikuchi, A.; Baba, T.; Futatsugi, A.; Sato, I.; et al. ESCRT-0 dysfunction compromises autophagic degradation of protein aggregates and facilitates ER stress-mediated neurodegeneration via apoptotic and necroptotic pathways. Sci. Rep. 2016, 6, 24997. [CrossRef] [PubMed]

82. Tamai, K.; Tanaka, N.; Nara, A.; Yamamoto, A.; Nakagawa, I.; Yoshimori, T.; Ueno, Y.; Shimosegawa, T.; Sugamura, K. Role of Hrs in maturation of autophagosomes in mammalian cells. Biochem. Biophys. Res. Commun. 2007, 360, 721-727. [CrossRef] [PubMed]

83. Takahashi, Y.; Liang, X.; Hattori, T.; Tang, Z.; He, H.; Chen, H.; Liu, X.; Abraham, T.; Imamura-Kawasawa, Y.; Buchkovich, N.J.; et al. VPS37A directs ESCRT recruitment for phagophore closure. J. Cell Biol. 2019, 218, 3336-3354. [CrossRef] [PubMed]

84. Zhou, F.; Wu, Z.; Zhao, M.; Murtazina, R.; Cai, J.; Zhang, A.; Li, R.; Sun, D.; Li, W.; Zhao, L.; et al. Rab5-dependent autophagosome closure by ESCRT. J. Cell Biol. 2019, 218, 1908-1927. [CrossRef]

85. Wu, Y.; Cheng, S.; Zhao, H.; Zou, W.; Yoshina, S.; Mitani, S.; Zhang, H.; Wang, X. PI3P phosphatase activity is required for autophagosome maturation and autolysosome formation. EMBO Rep. 2014, 15, 973-981. [CrossRef]

86. Yu, Z.-Q.; Ni, T.; Hong, B.; Wang, H.-Y.; Jiang, F.-J.; Zou, S.; Chen, Y.; Zheng, X.-L.; Klionsky, D.J.; Liang, Y.; et al. Dual roles of Atg8-PE deconjugation by Atg4 in autophagy. Autophagy 2012, 8, 883-892. [CrossRef]

87. Zhao, Y.G.; Zhang, H. Autophagosome maturation: An epic journey from the ER to lysosomes. J. Cell Biol. 2019, 218, 757-770. [CrossRef]

88. Ganesan, D.; Cai, Q. Understanding amphisomes. Biochem. J. 2021, 478, 1959-1976. [CrossRef]

89. Pu, J.; Guardia, C.M.; Keren-Kaplan, T.; Bonifacino, J.S. Mechanisms and functions of lysosome positioning. J. Cell Sci. 2016, 129, 4329-4339. [CrossRef]

90. Nakamura, S.; Yoshimori, T. New insights into autophagosome-lysosome fusion. J. Cell Sci. 2017, 130, 1209-1216. [CrossRef]

91. Lőrincz, P.; Juhász, G. Autophagosome-lysosome fusion. J. Mol. Biol. 2020, 432, 2462-2482. [CrossRef] [PubMed]

92. Ebner, P.; Poetsch, I.; Deszcz, L.; Hoffmann, T.; Zuber, J.; Ikeda, F. The IAP family member BRUCE regulates autophagosomelysosome fusion. Nat. Commun. 2018, 9, 599. [CrossRef] [PubMed]

93. Nam, S.-E.; Cheung, Y.W.S.; Nguyen, T.N.; Gong, M.; Chan, S.; Lazarou, M.; Yip, C.K. Insights on autophagosome-lysosome tethering from structural and biochemical characterization of human autophagy factor EPG5. Commun. Biol. 2021, 4, 291. [CrossRef] [PubMed]

94. Tian, X.; Zheng, P.; Zhou, C.; Wang, X.; Ma, H.; Ma, W.; Zhou, X.; Teng, J.; Chen, J. DIPK2A promotes STX17- and VAMP7-mediated autophagosome-lysosome fusion by binding to VAMP7B. Autophagy 2020, 16, 797-810. [CrossRef] [PubMed]

95. Matsui, T.; Jiang, P.; Nakano, S.; Sakamaki, Y.; Yamamoto, H.; Mizushima, N. Autophagosomal YKT6 is required for fusion with lysosomes independently of syntaxin 17. J. Cell Biol. 2018, 217, 2633-2645. [CrossRef]

96. Tang, B.L. Syntaxin 16's newly deciphered roles in autophagy. Cells 2019, 8, 1655. [CrossRef]

97. Almurshidi, B.; Carver, W.; Scott, G.; Ray, S.K. Roles of miRNAs in spinal cord injury and potential therapeutic interventions. Neuroimmunol. Neuroinflamm. 2019, 6, 11. [CrossRef]

98. Liu, B.; Zheng, W.; Dai, L.; Fu, S.; Shi, E. Bone marrow mesenchymal stem cell derived exosomal miR-455-5p protects against spinal cord ischemia reperfusion injury. Tissue Cell 2022, 74, 101678. [CrossRef]

99. Bisicchia, E.; Sasso, V.; Catanzaro, G.; Leuti, A.; Besharat, Z.M.; Chiacchiarini, M.; Molinari, M.; Ferretti, E.; Viscomi, M.T.; Chiurchiù, V. Resolvin D1 halts remote neuroinflammation and improves functional recovery after focal brain damage Via ALX/FPR2 receptor-regulated microRNAs. Mol. Neurobiol. 2018, 55, 6894-6905. [CrossRef]

100. Denton, D.; Kumar, S. Autophagy-dependent cell death. Cell Death Differ. 2019, 26, 605-616. [CrossRef]

101. Doherty, J.; Baehrecke, E.H. Life, death and autophagy. Nat. Cell Biol. 2018, 20, 1110-1117. [CrossRef] [PubMed]

102. Saleem, S. Apoptosis, autophagy, necrosis and their multi galore crosstalk in neurodegeneration. Neuroscience 2021, $469,162-174$. [CrossRef] [PubMed]

103. Chen, Q.; Kang, J.; Fu, C. The independence of and associations among apoptosis, autophagy, and necrosis. Signal Transduct. Target. Ther. 2018, 3, 18. [CrossRef] [PubMed]

104. Zhang, H.; Dong, X.; Zhao, R.; Zhang, R.; Xu, C.; Wang, X.; Liu, C.; Hu, X.; Huang, S.; Chen, L. Cadmium results in accumulation of autophagosomes-dependent apoptosis through activating Akt-impaired autophagic flux in neuronal cells. Cell Signal. 2019, 55, 26-39. [CrossRef] [PubMed] 
105. Ghavami, S.; Shojaei, S.; Yeganeh, B.; Ande, S.R.; Jangamreddy, J.R.; Mehrpour, M.; Christoffersson, J.; Chaabane, W.; Moghadam, A.R.; Kashani, H.H.; et al. Autophagy and apoptosis dysfunction in neurodegenerative disorders. Prog. Neurobiol. 2014, 112, 24-49. [CrossRef]

106. Miller, D.R.; Cramer, S.D.; Thorburn, A. The interplay of autophagy and non-apoptotic cell death pathways. Int. Rev. Cell Mol. Biol. 2020, 352, 159-187.

107. Ray, S.K. Modulation of autophagy for neuroprotection and functional recovery in traumatic spinal cord injury. Neural Regen. Res. 2020, 15, 1601-1612. [CrossRef]

108. Fang, B.; Li, X.-Q.; Bao, N.-R.; Tan, W.-F.; Chen, F.-S.; Pi, X.-L.; Zhang, Y.; Ma, H. Role of autophagy in the bimodal stage after spinal cord ischemia reperfusion injury in rats. Neuroscience 2016, 328, 107-116. [CrossRef]

109. Zhang, D.; Zhu, D.; Wang, F.; Zhu, J.-C.; Zhai, X.; Yuan, Y.; Li, C.-X. Therapeutic effect of regulating autophagy in spinal cord injury: A network meta-analysis of direct and indirect comparisons. Neural Regen. Res. 2020, 15, 1120-1132. [CrossRef]

110. Valencia, M.; Kim, S.R.; Jang, Y.; Lee, S.H. Neuronal autophagy: Characteristic features and roles in neuronal pathophysiology. Biomol. Ther. 2021, 29, 605-614. [CrossRef]

111. Roney, J.C.; Li, S.; Farfel-Becker, T.; Huang, N.; Sun, T.; Xie, Y.; Cheng, X.-T.; Lin, M.-Y.; Platt, F.M.; Sheng, Z.-H. Lipid-mediated motor-adaptor sequestration impairs axonal lysosome delivery leading to autophagic stress and dystrophy in Niemann-Pick type, C. Dev. Cell 2021, 56, 1452-1468.e8. [CrossRef] [PubMed]

112. Kuijpers, M.; Azarnia Tehran, D.; Haucke, V.; Soykan, T. The axonal endolysosomal and autophagic systems. J. Neurochem. 2021, 158, 589-602. [CrossRef] [PubMed]

113. Maday, S.; Holzbaur, E.L.F. Compartment-specific regulation of autophagy in primary neurons. J. Neurosci. 2016, 36, 5933-5945. [CrossRef] [PubMed]

114. Ariosa, A.R.; Klionsky, D.J. Autophagy core machinery: Overcoming spatial barriers in neurons. J. Mol. Med. 2016, 94, 1217-1227. [CrossRef] [PubMed]

115. Li, R.; Jin, Y.; Li, Q.; Sun, X.; Zhu, H.; Cui, H. MiR-93-5p targeting PTEN regulates the NMDA-induced autophagy of retinal ganglion cells via AKT/mTOR pathway in glaucoma. Biomed. Pharmacother. 2018, 100, 1-7. [CrossRef] [PubMed]

116. Jiang, H.; Wang, Y.; Liang, X.; Xing, X.; Xu, X.; Zhou, C. Toll-like receptor 4 knockdown attenuates brain damage and neuroinflammation after traumatic brain injury via inhibiting neuronal autophagy and astrocyte activation. Cell Mol. Neurobiol. 2018, 38, 1009-1019. [CrossRef]

117. Liu, J.; Jiang, M.; Deng, S.; Lu, J.; Huang, H.; Zhang, Y.; Gong, P.; Shen, X.; Ruan, H.; Jin, M.; et al. miR-93-5p-Containing exosomes treatment attenuates acute myocardial infarction-induced myocardial damage. Mol. Ther. Nucleic Acids 2018, 11, 103-115. [CrossRef]

118. Wang, B.; Zhong, Y.; Huang, D.; Li, J. Macrophage autophagy regulated by miR-384-5p-mediated control of Beclin-1 plays a role in the development of atherosclerosis. Am. J. Transl. Res. 2016, 8, 606-614.

119. Zhou, Z.; Hu, B.; Lyu, Q.; Xie, T.; Wang, J.; Cai, Q. miR-384-5p promotes spinal cord injury recovery in rats through suppressing of autophagy and endoplasmic reticulum stress. Neurosci. Lett. 2020, 727, 134937. [CrossRef]

120. Zhang, H.; Yu, H.; Yang, H.; Zhan, Y.; Liu, X. miR-378-3p alleviates contusion spinal cord injury by negatively regulating ATG12. Int. J. Exp. Pathol. 2021, 102, 200-208. [CrossRef]

121. Zhao, J.; Chen, F.; Ma, W.; Zhang, P. Suppression of long noncoding RNA NEAT1 attenuates hypoxia-induced cardiomyocytes injury by targeting miR-378a-3p. Gene 2020, 731, 144324. [CrossRef] [PubMed]

122. Luo, H.-C.; Yi, T.-Z.; Huang, F.-G.; Wei, Y.; Luo, X.-P.; Luo, Q.-S. Role of long noncoding RNA MEG3/miR-378/GRB2 axis in neuronal autophagy and neurological functional impairment in ischemic stroke. J. Biol. Chem. 2020, 295, 14125-14139. [CrossRef] [PubMed]

123. Li, Y.; Jiang, J.; Liu, W.; Wang, H.; Zhao, L.; Liu, S.; Li, P.; Zhang, S.; Sun, C.; Wu, Y.; et al. microRNA-378 promotes autophagy and inhibits apoptosis in skeletal muscle. Proc. Natl. Acad. Sci. USA 2018, 115, E10849-E10858. [CrossRef] [PubMed]

124. Zhou, J.; Liao, W.; Yang, J.; Ma, K.; Li, X.; Wang, Y.; Wang, D.; Wang, L.; Zhang, Y.; Yin, Y.; et al. FOXO3 induces FOXO1-dependent autophagy by activating the AKT1 signaling pathway. Autophagy 2012, 8, 1712-1723. [CrossRef]

125. Sun, L.; Zhao, M.; Wang, Y.; Liu, A.; Lv, M.; Li, Y.; Yang, X.; Wu, Z. Neuroprotective effects of miR-27a against traumatic brain injury via suppressing FoxO3a-mediated neuronal autophagy. Biochem. Biophys. Res. Commun. 2017, 482, 1141-1147. [CrossRef]

126. Li, H.; Lu, C.; Yao, W.; Xu, L.; Zhou, J.; Zheng, B. Dexmedetomidine inhibits inflammatory response and autophagy through the circLrp1b/miR-27a-3p/Dram2 pathway in a rat model of traumatic brain injury. Aging 2020, 12, 21687-21705. [CrossRef]

127. Kim, J.; Fiesel, F.C.; Belmonte, K.C.; Hudec, R.; Wang, W.-X.; Kim, C.; Nelson, P.T.; Springer, W.; Kim, J. miR-27a and miR-27b regulate autophagic clearance of damaged mitochondria by targeting PTEN-induced putative kinase 1 (PINK1). Mol. Neurodegener. 2016, 11, 55. [CrossRef]

128. Jia, D.; Niu, Y.; Li, D.; Zhang, Q. microRNA-223 alleviates lipopolysaccharide-induced PC-12 cells apoptosis and autophagy by targeting RPH1 in spinal cord injury. Int. J. Clin. Exp. Pathol. 2017, 10, 9223-9232.

129. Bernard, A.; Jin, M.; González-Rodríguez, P.; Füllgrabe, J.; Delorme-Axford, E.; Backues, S.K.; Joseph, B.; Klionsky, D.J Rph1/KDM4 mediates nutrient-limitation signaling that leads to the transcriptional induction of autophagy. Curr. Biol. 2015, 25, 546-555. [CrossRef]

130. Liu, X.; Feng, Z.; Du, L.; Huang, Y.; Ge, J.; Deng, Y.; Mei, Z. The potential role of microRNA-124 in cerebral ischemia injury. Int. J. Mol. Sci. 2019, 21, 120. [CrossRef] 
131. Liu, K.; Yan, L.; Jiang, X.; Yu, Y.; Liu, H.; Gu, T.; Shi, E. Acquired inhibition of microRNA-124 protects against spinal cord ischemia-reperfusion injury partially through a mitophagy-dependent pathway. J. Thorac. Cardiovasc. Surg. 2017, 154, 1498-1508. [CrossRef] [PubMed]

132. Miao, W.; Yan, Y.; Bao, T.-H.; Jia, W.-J.; Yang, F.; Wang, Y.; Zhu, Y.; Yin, M.; Han, J. Ischemic postconditioning exerts neuroprotective effect through negatively regulating PI3K/Akt2 signaling pathway by microRNA-124. Biomed. Pharmacother. 2020, 126, 109786. [CrossRef] [PubMed]

133. Guan, C.; Luan, L.; Li, J.; Yang, L. miR-212-3p improves rat functional recovery and inhibits neurocyte apoptosis in spinal cord injury models via PTEN downregulation-mediated activation of AKT/mTOR pathway. Brain Res. 2021, 1768, 147576. [CrossRef] [PubMed]

134. Ucar, A.; Gupta, S.K.; Fiedler, J.; Erikci, E.; Kardasinski, M.; Batkai, S.; Dangwal, S.; Kumarswamy, R.; Bang, C.; Holzmann, A.; et al. The miRNA-212/132 family regulates both cardiac hypertrophy and cardiomyocyte autophagy. Nat. Commun. 2012, 3, 1078. [CrossRef] [PubMed]

135. Oh, J.Y.; Kim, E.H.; Lee, Y.-J.; Sai, S.; Lim, S.H.; Park, J.W.; Chung, H.K.; Kim, J.; Vares, G.; Takahashi, A.; et al. Synergistic autophagy effect of miR-212-3p in zoledronic acid-treated in vitro and orthotopic in vivo models and in patient-derived osteosarcoma cells. Cancers 2019, 11, 1812. [CrossRef]

136. Ramalinga, M.; Roy, A.; Srivastava, A.; Bhattarai, A.; Harish, V.; Suy, S.; Collins, S.; Kumar, D. microRNA-212 negatively regulates starvation induced autophagy in prostate cancer cells by inhibiting SIRT1 and is a modulator of angiogenesis and cellular senescence. Oncotarget 2015, 6, 34446-34457. [CrossRef]

137. Cai, L.; Liu, X.; Guo, Q.; Huang, Q.; Zhang, Q.; Cao, Z. miR-15a attenuates peripheral nerve injury-induced neuropathic pain by targeting AKT3 to regulate autophagy. Genes Genom. 2020, 42, 77-85. [CrossRef]

138. Huang, N.; Wu, J.; Qiu, W.; Lyu, Q.; He, J.; Xie, W.; Xu, N.; Zhang, Y. miR-15a and miR-16 induce autophagy and enhance chemosensitivity of camptothecin. Cancer Biol. Ther. 2015, 16, 941-948. [CrossRef]

139. Wang, B.; Huang, J.; Li, J.; Zhong, Y. Control of macrophage autophagy by miR-384-5p in the development of diabetic encephalopathy. Am. J. Transl. Res. 2018, 10, 511-518.

140. Li, Y.; Zhou, D.; Ren, Y.; Zhang, Z.; Guo, X.; Ma, M.; Xue, Z.; Lv, J.; Liu, H.; Xi, Q.; et al. miR-223 restrains autophagy and promotes CNS inflammation by targeting ATG16L1. Autophagy 2019, 15, 478-492. [CrossRef]

141. He, Z.; Chen, H.; Zhong, Y.; Yang, Q.; Wang, X.; Chen, R.; Guo, Y. microRNA-223 targeting ATG16L1 affects microglial autophagy in the kainic acid model of temporal lobe epilepsy. Front. Neurol. 2021, 12, 704550. [CrossRef] [PubMed]

142. Hu, J.; Wang, X.; Cui, X.; Kuang, W.; Li, D.; Wang, J. Quercetin prevents isoprenaline-induced myocardial fibrosis by promoting autophagy via regulating miR-223-3p/FOXO3. Cell Cycle 2021, 20, 1253-1269. [CrossRef] [PubMed]

143. Long, C.; Cen, S.; Zhong, Z.; Zhou, C.; Zhong, G. FOXO3 is targeted by miR-223-3p and promotes osteogenic differentiation of bone marrow mesenchymal stem cells by enhancing autophagy. Hum. Cell. 2021, 34, 14-27. [CrossRef]

144. Zhou, Y.; Chen, E.; Tang, Y.; Mao, J.; Shen, J.; Zheng, X.; Xie, S.; Zhang, S.; Wu, Y.; Liu, H.; et al. miR-223 overexpression inhibits doxorubicin-induced autophagy by targeting FOXO3a and reverses chemoresistance in hepatocellular carcinoma cells. Cell Death Dis. 2019, 10, 843. [CrossRef]

145. Wang, P.; Liang, J.; Li, Y.; Li, J.; Yang, X.; Zhang, X.; Han, S.; Li, S.; Li, J. Down-regulation of miRNA-30a alleviates cerebral ischemic injury through enhancing beclin 1-mediated autophagy. Neurochem. Res. 2014, 39, 1279-1291. [CrossRef]

146. Sun, B.; Ou, H.; Ren, F.; Guan, Y.; Huan, Y.; Cai, H. Propofol protects against cerebral ischemia/reperfusion injury by downregulating long noncoding RNA SNHG14. ACS Chem. Neurosci. 2021, 12, 3002-3014. [CrossRef] [PubMed]

147. Li, L.; Jiang, H.-K.; Li, Y.-P.; Guo, Y.-P. Hydrogen sulfide protects spinal cord and induces autophagy via miR-30c in a rat model of spinal cord ischemia-reperfusion injury. J. Biomed. Sci. 2015, 22, 50. [CrossRef] [PubMed]

148. Yang, X.; Zhong, X.; Tanyi, J.L.; Shen, J.; Xu, C.; Gao, P.; Zheng, T.M.; DeMichele, A.; Zhang, L. miR-30d Regulates multiple genes in the autophagy pathway and impairs autophagy process in human cancer cells. Biochem. Biophys. Res. Commun. 2013, 431, 617-622. [CrossRef] [PubMed]

149. Chakrabarti, M.; Klionsky, D.J.; Ray, S.K. miR-30e Blocks autophagy and acts synergistically with proanthocyanidin for inhibition of AVEN and BIRC6 to increase apoptosis in glioblastoma stem cells and glioblastoma SNB19 Cells. PLoS ONE 2016, 11, e0158537. [CrossRef]

150. Zhao, F.; Qu, Y.; Wang, H.; Huang, L.; Zhu, J.; Li, S.; Tong, Y.; Zhang, L.; Li, J.; Mu, D. The effect of miR-30d on apoptosis and autophagy in cultured astrocytes under oxygen-glucose deprivation. Brain Res. 2017, 1671, 67-76. [CrossRef]

151. Zhao, F.; Qu, Y.; Zhu, J.; Zhang, L.; Huang, L.; Liu, H.; Li, S.; Mu, D. miR-30d-5p Plays an important role in autophagy and apoptosis in developing rat brains after hypoxic-ischemic Injury. J. Neuropathol. Exp. Neurol. 2017, 76, 709-719. [CrossRef] [PubMed]

152. Jiang, M.; Wang, H.; Jin, M.; Yang, X.; Ji, H.; Jiang, Y.; Zhang, H.; Wu, F.; Wu, G.; Lai, X.; et al. Exosomes from miR-30d-5p-adscs reverse acute ischemic stroke-induced, autophagy-mediated brain injury by promoting M2 microglial/macrophage polarization. Cell Physiol. Biochem. 2018, 47, 864-878. [CrossRef] [PubMed]

153. Xu, Q.; Guohui, M.; Li, D.; Bai, F.; Fang, J.; Zhang, G.; Xing, Y.; Zhou, J.; Guo, Y.; Kan, Y. lncRNA C2dat2 facilitates autophagy and apoptosis via the miR-30d-5p/DDIT4/mTOR axis in cerebral ischemia-reperfusion injury. Aging 2021, 13, 11315-11335. [CrossRef] [PubMed] 
154. Guo, X.D.; He, X.G.; Yang, F.G.; Liu, M.Q.; Wang, Y.D.; Zhu, D.X.; Zhang, G.Z.; Ma, Z.J.; Kang, X.W. Research progress on the regulatory role of microRNAs in spinal cord injury. Regen Med. 2021, 16, 465-476. [CrossRef] [PubMed]

155. Fowler, A.J.; Ahn, J.; Hebron, M.; Chiu, T.; Ayoub, R.; Mulki, S.; Ressom, H.; Torres-Yaghi, Y.; Wilmarth, B.; Pagan, F.L.; et al. CSF microRNAs reveal impairment of angiogenesis and autophagy in Parkinson disease. Neurol. Genet. 2021, 7, e633. [CrossRef]

156. Guo, J.; Yang, Z.; Yang, X.; Li, T.; Liu, M.; Tang, H. miR-346 functions as a pro-survival factor under ER stress by activating mitophagy. Cancer Lett. 2018, 413, 69-81. [CrossRef] 